\title{
Thermoeconomic Optimization of a Renewable Polygeneration System Serving a Small Isolated Community
}

\author{
Francesco Calise $^{1, *}$, Massimo Dentice d'Accadia ${ }^{1, \dagger}$, Antonio Piacentino ${ }^{2, \dagger}$ and \\ Maria Vicidomini ${ }^{1, \dagger}$
}

1 Department of Industrial Engineering, University of Naples Federico II, 80125 Naples, Italy; E-Mails: dentice@unina.it (M.D.A.); maria.vicidomini@unina.it (M.V.)

2 Department of Energy, Information Engineering and Mathematical Models, University of Palermo, 90128 Palermo, Italy; E-Mail: piacentino@ dream.unipa.it

$\dagger$ These authors contributed equally to this work.

* Author to whom correspondence should be addressed; E-Mail: frcalise@ unina.it; Tel.: +39-081-768-2301; Fax: +39-081-239-0364.

Academic Editor: Josep M. Guerrero

Received: 28 November 2014 / Accepted: 20 January 2015 / Published: 30 January 2015

\begin{abstract}
During the last years, special attention has been paid to renewable polygeneration technologies, able of simultaneously producing thermal, cooling, electrical energy and desalinated water from seawater. This paper focuses on an innovative polygeneration system driven by renewable energy sources, including the following technologies: hybrid photovoltaic/thermal collectors, concentrating parabolic trough (CPVT), a biomass heater, a single-stage absorption chiller and a multiple-effect distillation desalination system. The system is designed to cover the base load of an isolated small community. In previous papers, the dynamic simulation model about plant operation is discussed. In this paper, a detailed exergy, economic and environmental analysis of the plant is presented. In addition, the plant was optimized using different objective functions, applying the Design of Experiment (DoE) methodology which evaluates the sensitivity of the different objective functions with respect to the selected design parameters. The results show that an increase of the storage volume is generally negative, whereas increasing the solar field area involves an increase of the exergy destruction rate, but also an improvement of the CPVT exergy output provided; the final result is an increase of both the exergy efficiency and the economic profitability of the polygeneration system.
\end{abstract}


Keywords: solar heating and cooling; photovoltaic/thermal collectors (PVT); solar desalination; multiple-effect distillation (MED); exergy analysis; exergoeconomics

\section{Introduction}

During the last few years, worldwide energy consumption has increased rapidly, basically due to the dramatic growth of emerging countries. Unfortunately, the majority of such energy is obtained from fossil or non-renewable fuels (such as: gas, oil, coal, nuclear), whose future availability and environmental impact are becoming a severe issue. Presently, conventional energy conversion technologies, based on the utilization of fossil fuels, are usually the most profitable option from an economical point of view. In fact, renewable energy sources become economically competitive only when they are supported by public funding. However, in the last decade, the fossil fuel cost has been rapidly increasing and the capital cost of renewable technologies has been simultaneously and dramatically decreasing. Therefore, it can be expected that some renewable technologies will become economically competitive with conventional ones in the next future. In addition, the consumption of fresh water is increasing dramatically, so that several scientists consider such a resource crucial for the future, even more so than energy. As a consequence, a more sustainable energy supply scheme should be considered in order to achieve a sustainable and environmental friendly worldwide development [1]. In this framework, renewable energies are considered one of the most promising technologies. In particular, the present work focuses on a combination of solar energy and biomass, used to produce simultaneously thermal energy for heating and cooling, electrical energy and desalinated water. The following technologies are simultaneously included in the system: solar heating and cooling (SHC), concentrating photovoltaic-thermal collectors (CPVT) and multiple-effect distillation (MED) for seawater desalination.

Solar heating and cooling (SHC) is an emerging technology which allows one to produce cooling energy using solar irradiation; during the winter solar energy is used for space heating purposes. SHC technology is particularly attractive in summer, when the demand for cooling is often simultaneous to the availability of solar radiation [2]. The majority of SHC systems realized up to now are equipped with medium temperature solar thermal collectors (e.g., evacuated tubes solar collectors) and single-stage absorption chiller, whereas alternative configurations (adsorption chillers, desiccant cooling, steam ejection, etc.) are very rare [3-6]. Photovoltaic/thermal collectors (PVT) are an emerging solar technology, too. The basic principle of a PVT is simple, since it can be obtained by a conventional thermal collector, equipping the absorber with a suitable PV layer [7]. The thermal energy absorbed is distributed to a fluid (typically air or water), whereas the PV produces electricity $[8,9]$. In order to reduce the expensive PV active area, PVT are often equipped with concentrating devices, in concentrating PVT collectors (CPVT) [8-11]. Usually, CPVT operate at higher temperature than PVT. Therefore, in case of CPVT collectors, novel PV materials are often used, such as multi-junction solar cells. In fact, differently from conventional silicon PV cells, such PV materials can achieve reasonable electrical efficiency even at high operating temperature [10,12].

Several technologies have been used to face the drinkable water scarcity by desalting seawater or brackish water. In spite of the fact that more than $60 \%$ of global volume capacity for desalination is 
represented by electrical or mechanical systems (with a large prevalence of reverse osmosis, RO) [13], thermal systems still play a primary role in regions characterized by lower fossil fuel prices [14] or integrated in dual purpose plants, which simultaneously produce electricity and use low-grade heat cascades to produce fresh water [15-17]. In fact, the most common technologies for seawater desalination, i.e., the multi-stage flash (MSF) [18] and the multiple-effect distillation (MED) [19] systems, are both characterized by high unit energy consumptions, in the order of $30-50 \mathrm{kWh}$ thermal and 3-5 $\mathrm{kWh}_{\text {electricity }}$ per $\mathrm{m}^{3}$ of fresh water, thus resulting in high production cost; however, as the motive steam or hot water may be required at temperature as low as $75-90{ }^{\circ} \mathrm{C}$, evident opportunities may be exploited to drive the process via heat cascades or low-temperature renewable energy sources [20].

All the above mentioned technologies (SHC, CPVT and MED) have been considered by the authors in recent works, where such novel systems were coupled with a biomass heater [21] and geothermal wells [22], designing and simulating a novel system able to simultaneously produce electricity, thermal energy for heating and cooling, and fresh water. These recent works only focused on the energy and economic analysis of the novel renewable polygeneration system proposed. In the present paper, on the basis of the system layout presented in reference [21], a further implementation has been performed, aiming at presenting a detailed exergy analysis and several energy, exergy and economic optimizations of the system under investigation.

In fact, as shown in the previous papers [21,22], several researchers have investigated SHC, CPVT, MSF and MED subsystems one at the time. However, very few works are available in the literature investigating their integration in a single system. Furthermore, even for the single subsystems, very few studies are available in which both exergy and economic aspects are addressed.

The literature regarding exergy analyses of SHC and CPVT systems is very rich. As an example, Koroneos presented an exergy and environmental analysis for a SHC system, concluding that the exergy efficiency is low, but the environmental impact is low, too [23]. A similar work was performed by Onan et al., concluding that the exergy loss in the solar collector varies between $10 \%$ and $70 \%$, whereas the exergy loss in the generator ranges from 5\% to 8\% [24]. Similarly, several papers are available in which different aspects of the exergy analysis of CPVT systems are investigated. As an example, Calise et al. presented a detailed mono-dimensional energy and exergy analysis of a novel parabolic CPVT collector, showing that the exergy efficiency is low since the system is affected by severe unavoidable exergy losses, such as the ones due to solar radiation [25].

Conversely, a lower number of papers is available presenting exergy analyses of desalination plants. In particular, a first study regarding exergy destruction in a multiple-effect seawater desalination plant was performed by El-Nashar et al. The study was based on measured data regarding a desalination plant operating in Abu Dhabi. The authors found that the major exergy destruction was due to the vacuum pumps. Major exergy losses were also associated with the effluent streams of distillate, brine blow-down and seawater [26]. A similar study for a MSF desalination plant was developed by Nafey et al. The authors found that the exergy flow related to the distilled water was very small (0.20 MW), compared to the overall exergy input (10.7 MW). Exergy destruction was mainly due to heat and stream rejections and to the irreversibilities occurring in the components of the system [27]. A more complex arrangement was investigated by Sharaf et al. who analyzed a more complex plant including a MED, an Organic Rankine Cycle and a field of solar parabolic trough collectors (PTC) [28]. The authors concluded that the best configuration is achieved for a 16-20 stages MED supplied at 
$70-75^{\circ} \mathrm{C}$. A comprehensive presentation regarding the methodology to be used in the exergy analysis of desalination systems is given by Sharqawy et al. [29]. The authors include a detailed description of the thermodynamic models. A case study is also presented for a MSF system using real plant operation data. The ideal gas mixture model was found to be responsible for the major errors in the exergy analysis. A further exergy analysis of a MSF plant is presented by Al-Weshahi [30]. The authors found a very low exergy efficiency of the system (5.8\%), concluding that the exergy destruction rate is lowin the first stage, increasing gradually in heat recovery stages and sharply in heat rejection stages. A recent paper by Nematollahi presents a novel solar desalination system based on a solar collector and a on a humidification tower [31]. The system was analysed from both theoretical and experimental points of view, aiming also at calculating the exergy performance. They found a very high exergy efficiency (>99\%) increasing for lower humidification tower length, lower inlet air temperature, and higher tower diameter. Recently, the exergy analysis was also applied to a vapour compression flash seawater desalination plant by Jin et al. [32]. This study was performed from both theoretical and experimental points of view. The highest exergy efficiency was achieved by the flash tank followed by heat exchangers and vapour compressor.

The literature review also revealed a number of papers investigating separately the thermoeconomic optimizations of MED [33-40], SHC [41-45] and CPVT [46-48] systems. As an example, a paper by Manesh et al. presented a new procedure based on exergoeconomic optimization to find optimal coupling of site utility and MED-reverse osmosis desalination system [49].

However, in the authors' knowledge, none of the papers available in the open literature applies both exergy and exergoeconomic techniques to such a complex renewable polygeneration system as the one presented in this paper. The analysis presented here also includes a detailed description of the exergy and exergoeconomic models for all the components of the system and a comprehensive analysis of the related results.

In summary, the literature review performed by the authors showed that a number of papers investigated from the exergy and thermoeconomic points of view MED, CPVT and SHC subsystem, one at the time. However, none of the studies available in literature performs a comprehensive exergy analysis and thermoeconomic optimization of the complex renewable polygeneration system, including simultaneously MED, CPVT and SHC technologies. Therefore, the present study aims at improving the knowledge on this topic, implementing two major innovations with respect to the findings available in literature, namely.

A detailed exergy analysis, aiming at evaluating the instantaneous exergy destruction rates in all the components of the system, was performed. Similarly, the analysis allows one to integrate the exergy destruction rates on different time bases (weeks, months, year, etc.). Such calculations allow one to evaluate the magnitude and the location of irreversibilities, suggesting possible actions to improve the exergy efficiency of the system.

A detailed exergo-economic optimization, based on the computer-aided Design of Experiments (DoE) technique, was also introduced [50]. Such statistical optimization technique allows one to predict the shape of the optimum response surface of whatever selected objective function, using a reduced number of simulations. Differently by conventional heuristic and/or deterministic optimizations [41], that only return the optimum set of the design parameters, with such technique the sensitivity of the design variables to the shape of the optimum response surface can be also analyzed. Such tool was already used by the authors in previous works, in order to optimize a SHC system [51]. 


\section{System Layout}

As mentioned in the previous section, the system investigated in this paper combines SHC, CPVT, biomass heater and MED technologies, so it can be considered as a polygeneration system, providing as output different energy (electricity, cool and heat) and mass flows (desalted water). For sake of brevity, the system will be named Renewable Polygeneration System (RPS). A simplified layout of the system under investigation is shown in Figure 1, where only the main components and nodes are displayed. The RPS layout investigated in this paper was diffusely presented in reference [20].

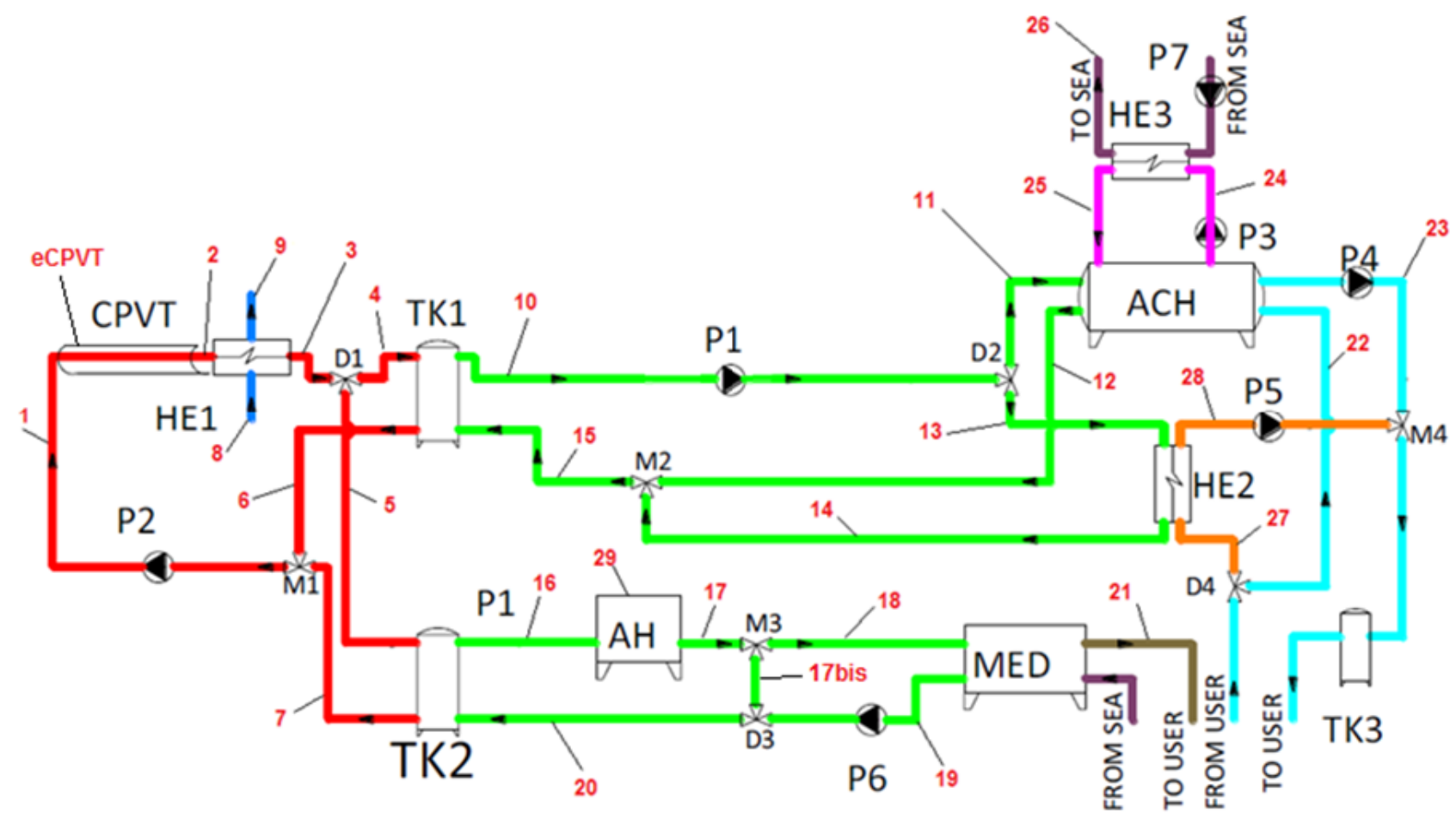

Figure 1. System Layout.

The system consists of the following main loops:

(1) Solar Collector Fluid, (red line in Figure 1), SCF: pressurized water flowing from the source sides of the tanks to the solar field;

(2) Hot Fluid, (green line in Figure 1), HF: pressurized water flowing from the load sides of the tanks to the devices using solar thermal energy;

(3) Cooling Water, (fuchsia line in Figure 1), CW: water flowing in the condenser and absorber of the Absorption Chiller (ACH);

(4) Chilled Water, (sky blue line in Figure 1), CHW: water flowing in the evaporator of the Absorption Chiller (ACH);

(5) Domestic Hot Water, (orange line in Figure 1), DHW: water supplying sanitary devices;

(6) Hot Water, HW: water supplying space heating devices;

(7) Sea Water, (violet line in Figure 1), SW: water supplied to the MED, in order to be desalinated, or to the heat exchanger used for cooling the $\mathrm{ACH}$;

(8) Desalinated Water, (brown line in Figure 1), DW: fresh water produced by the MED and supplied to final users. 
The following main components are included in the system [20]:

- a Solar Collector field, CPVT, consisting of concentrating parabolic trough solar collectors whose absorber is covered by a triple-junction PV layer; the beam radiation is concentrated on a triangular receiver, placed on the focus of the parabola, on which a multi-junction PV panel is laminated; the triangular receiver is equipped with an internal tube, in which a cooling fluid flows; the system is also equipped with a one-axis tracking system, typical of parabolic trough solar thermal collectors; the PVT can operate up to $100{ }^{\circ} \mathrm{C}$;

- a Thermal Storage system (TK1), supplying heat for space heating and cooling purposes, consisting of a set of stratified vertical hot storage tanks, equipped with inlet stratification devices: the entering position of the inlet fluid is varied so that fluid and tank temperature are equal;

- a Thermal Storage system (TK2), supplying heat for seawater desalination, consisting of a set of stratified vertical hot storage tanks, equipped with inlet stratification devices: the entering position of the inlet fluid is varied so that fluid and tank temperature are equal;

- a plate-fin heat exchanger in the solar loop (HE1), used to produce Domestic Hot Water when the solar irradiation is higher than the ACH (or the HE2) thermal demand;

- a plate-fin heat exchanger in the HW loop (HE2), transferring heat from the HF to the hot water $(\mathrm{CHW})$ to be supplied to the fan-coils during the winter;

- a plate-fin heat exchanger in the CW/SW loops (HE3), cooling the CW loop using the seawater, SW;

- a $\quad$ iBr- $\mathrm{H}_{2} \mathrm{O}$ single-effect absorption chiller $(\mathrm{ACH})$, whose generator is fed by the hot fluid (HF) provided by the solar field; the condenser and the absorber of the $\mathrm{ACH}$ are cooled by seawater, through the cooling water loop $(\mathrm{CW})$;

- a Multiple-Effect Distillation (MED) unit, producing desalinated water from seawater;

- a wood-chip fired Auxiliary Heater (AH), providing auxiliary thermal energy to the MED unit;

- $\quad$ some fixed-volume pump (P1, P3, P4, P5, P6 and P7) for the HF, HW, SW, CHW and CW loops;

- a variable-speed pump (P2) for the SCF loop;

- an inertial chilled/hot water storage tank (TK3), included in order to reduce the number of start-up and shut-down events for the absorption chiller $\mathrm{ACH}$;

- $\quad$ some Balance of the Plant (BOP) equipment (the majority not displayed in Figure 1 for sake of simplicity), such as pipes, mixers, diverters, valves, and controllers required for the system operations.

Solar energy is used to increase the CPVT outlet temperature up to the fixed set point, Tset,CPVT. Two different values are assumed for such set-point, $\mathrm{T}_{\text {set,CPVT,summ }}$ and $\mathrm{T}_{\text {set,CPVT,wint }}$ during the summer and winter operation modes, respectively. Set-point temperatures are achieved by the variable-speed pump P2. Such controller also deactivates the flow in case of possible heat dissipation. When CPVT outlet temperature is higher than $100{ }^{\circ} \mathrm{C}$, heat exchanger HE1 is activated, producing Domestic Hot Water (DHW) and simultaneously cooling the SCF to $100^{\circ} \mathrm{C}$. In all the other cases HE1 is by-passed. A sensor measures the temperature at the top side of TK1; when such temperature is lower than a fixed set-point, TTK,set, assumed equal to $T_{\text {set,CPVT }}-\Delta T_{T K}$, and/or when this temperature is below MED design temperature $\left(75^{\circ} \mathrm{C}\right)$, the valves supply the SCF only to TK1. Conversely, when the top 
temperature of TK1 reaches the maximum between $\mathrm{TTK}$,set and $75^{\circ} \mathrm{C}$, the $\mathrm{SCF}$ is brought to the TK2, supplying heat to the MED subsystem. On the other side of TK2, the flow passes through a biomass-fired (wood chip) heater, providing auxiliary heat to the HF, supplying heat to the MED subsystem. During the summer the hot flow coming from TK1 supplies the generator of the ACH. Conversely, during the winter, such flow supplies the hot side of the heat exchanger HE2. The pump P1 is managed by a controller, measuring the temperature of the fluid exiting from the TK1. When such temperature is lower than a minimum allowable value $\left(45^{\circ} \mathrm{C}\right.$ and $75^{\circ} \mathrm{C}$, respectively in winter and in summer), $\mathrm{P} 1$ is deactivated, so that the solar energy can heat TK1 up to the minimum temperature required. The condenser and absorber of the $\mathrm{ACH}$ are indirectly coupled by seawater, avoiding the use of a cooling tower. An indirect exchange by heat exchanger HE3 is required in order to avoid corrosion of the ACH by seawater. This system is assumed to be used as a retrofit/repowering of an existing and larger Heating and Cooling system. Therefore, all the cooling and heating energy produced by the RPS is assumed to be consumed by the end user. Such complex control system is managed by a number of different types of controllers, on/off with hysteresis, feedback, proportional, etc. Finally, all the devices, including the MED subsystem, are completely deactivated when the incident solar radiation is zero.

It is worth noting that the system under investigation was supposed to be located in Naples, in the South of Italy (latitude $40^{\circ} 50^{\prime} \mathrm{N}$, longitude $14^{\circ} 15^{\prime} \mathrm{E}$ ). Therefore, all weather data (ambient temperature, humidity, solar radiation, wind velocity, etc.) used in the simulation were obtained from Meteonorm database for that location. As discussed in reference [21], the system is assumed to be used as a retrofit/repowering of an existing and larger Heating and Cooling system. Therefore, the entire cooling and heating energy provided by the RPS is assumed to be dispatched to end users.

\section{Simulation Model}

The RPS polygeneration system described in the previous section was dynamically simulated by TRNSYS [51], which is a well-known software diffusely adopted for both commercial and academic purposes, including a large library of built-in components, often validated by experimental data. This model is based on a well-known approach, assuming stationary conditions for the non-capacitive components, whereas the capacitive ones (pipes, tanks, etc.) account for the unsteady terms in the energy balances. Such approach allows one to simulate in detail complex systems when the simulation time-step is sufficiently large (minutes). Conversely, this approach does not allow one to simulate in detail, all the transient phenomena occurring at the start-up and shut-down of the components. However, these phenomena are commonly considered negligible in the operation of such system. As a consequence, the approach implemented in TRNSYS is widely adopted in literature for the simulation of several energy systems [51]. As mentioned above, the RSP layout investigated in this paper was presented in a recent study by the authors where a detailed description of all the simulation models is provided [20]. However, the model presented in reference [20] only included mass and energy balances which allow one to calculate system temperatures, pressures, heat and mechanical flows and mass flow rates. As mentioned in Section 1, this model has been here implemented including a detailed transient exergy analysis of all the components included in the system. Simultaneously a special model has been implemented for the calculation of the exergy, thermoeconomic and environmental performance of the system. As a consequence, the following section will present 
only these new models since the reader can refer to the previous paper [20] for further details regarding the simulation models.

\subsection{Exergy Model}

The majority of the components included in the system do not involve chemical reactions. Therefore, for such components, exergy balances can be written considering the sole physical exergy related to the material and energy streams entering and exiting each component. However, in case of MED unit and biomass heater burner, some important chemical processes occur. Therefore, in this case exergy balances must also consider the chemical exergy related to the streams involved in those components [25]. Furthermore, it is worth noting that for all the liquid fluids included in the systems, physical exergy can be calculated as:

$$
e x_{p h}=\left(h-h_{a}\right)-T_{a}\left(s-s_{a}\right)=c\left[\left(T-T_{a}\right)+v\left(p-p_{a}\right)\right]-T_{a} c \ln \left(\frac{T}{T_{a}}\right)
$$

However, as usual in liquids, the term $v\left(p-p_{a}\right)$ is often negligible with respect to the remaining ones. For example, results presented in reference [25] show that exergy related to pressure drops is absolutely negligible with respect to the one related to temperature differences. Therefore, the previous equation can be simplified as follows:

$$
e x_{p h}=\left(h-h_{a}\right)-T_{a}\left(s-s_{a}\right)=c\left(T-T_{a}\right)-c T_{a} \ln \left(\frac{T}{T_{a}}\right)
$$

where $c$ is the fluid specific heat and $T$ and $p$ are temperature and pressure of the considered state point. $T_{a}$ and $p_{a}$ respectively indicate the temperature and pressure of the considered dead state. Variable values of dead-state temperature and pressures could be adopted, to properly reflect the continuously variable ambient air conditions. However, as clearly shown in [52] "the results of energy and exergy analysis are usually not significantly sensitive to reasonable variations in these properties"; also, assuming a fixed dead state allows to make exergy to be a state function for any working fluid, rather than a co-property of instantaneous ambient and fluid state. In our case a conventional ambient temperature $T_{a}=25{ }^{\circ} \mathrm{C}$ was assumed, that is a value rather close to the annual average outdoor air temperature. Similarly, a constant dead state pressure, $p_{a}=1.013 \mathrm{bar}$, was assumed.

Equation (2) can be used in order to calculate exergy per unit mass for all the streams. The exergy flow due to electrical power produced is numerically equal to the electricity produced [53]. The exergy flows due to the heat transfer can be evaluated correcting the heat flow by the corresponding Carnot factor [53]:

$$
\dot{E} x_{\dot{Q}}=\dot{Q}\left(1-\frac{T_{a}}{T}\right)
$$

However, considering that all these heat transfers are related to losses toward the environment, temperature $T$ is equal to the environmental temperature $T_{a}$ and therefore the associated exergy flow is null.

On the basis of these assumptions, the exergy balances can be written taking into account that the capacitive terms are included only for those components, such as tanks, whose energy model considers 
their thermal capacity. Thus, the exergy theory can be applied in order to calculate exergy destruction rates and exergy efficiencies for all components [53]. In the followings, these calculations are shown for the main components of the system, whereas they are omitted for simple components (pipes, valves, pumps and mixers) for sake of brevity.

\subsubsection{CPVT Collector}

Some special calculations must be performed in order to evaluate the exergy stream due to renewable energy sources. In particular, the calculation of the exergy flow due to the solar radiation can be performed using different approaches (Jeter, Petela and others) [54]. Such approaches ("technical boundary approaches") differ for the selection of the temperature of the sun. A completely different approach ("physical boundary approach") disregards the conversion of solar energy into heat in the solar collector. In this paper, according to the best practise available in literature for the "technical boundary approach" [54], this calculation is performed by the Petela theorem, in which the sun temperature is set at $4077{ }^{\circ} \mathrm{C}$ (3/4 of the corresponding black body temperature) [55]:

$$
\dot{E} x_{\text {sun }}=A \cdot I \cdot\left(1-\frac{T_{a}}{T_{\text {sun }}}\right)
$$

Therefore, the exergy destruction and the exergy efficiency of the CPVT are respectively as follows:

$$
\begin{gathered}
\dot{E} x_{d, C P V T}=\dot{E} x_{\text {sun }}-\dot{W}_{C P V T}-\left(\dot{E} x_{2}-\dot{E} x_{1}\right) \\
\eta_{e x, C P V T}=\frac{\dot{W}_{C P V T}+\left(\dot{E} x_{2}-\dot{E} x_{1}\right)}{\dot{E} x_{\text {sun }}}
\end{gathered}
$$

\subsubsection{Biomass Heater}

Similarly, the exergy flow related to the biomass entering the boiler can be calculated, considering its chemical exergy of reaction. According to the results suggested by Song et al. [56], exergy flow related to the biomass used by the boiler is:

$$
\dot{E} x_{\text {biomass }}=\dot{m}_{\text {biomass }} \text { ex } x_{c, \text { biomass }}
$$

In case of wood chip biomass the specific chemical exergy, ex $x_{c, \text { biomass }}$, is estimated in $19.37 \times 10^{3} \mathrm{~kJ} / \mathrm{kg}[56]$.

Therefore, the exergy destruction and the exergy efficiency are respectively as follows:

$$
\begin{gathered}
\dot{E} x_{d, A H}=\dot{E} x_{\text {biomass }}-\left(\dot{E} x_{17}-\dot{E} x_{16}\right) \\
\eta_{e x, \mathrm{AH}}=\frac{\left(\dot{E} x_{17}-\dot{E} x_{16}\right)}{\dot{E} x_{\text {biomass }}}
\end{gathered}
$$

\subsubsection{MED}

As concerns the exergy model of the MED unit, an introduction is needed. In theory, the chemical and physical (sum of the thermal and mechanical contributes) exergy flows associated with all the 
material streams should be calculated; however, since the destruction of mechanical exergy is essentially related with the pressure losses and can be quantified by the pumping power consumption, $W_{M E D}$, only the chemical and thermal exergy fractions will be calculated. Also, in order to simplify the analysis and calculate the exergy destruction and efficiency at system level, an appropriate boundary is fixed, that is represented by the bold dashed line in Figure 2, where the schematic representation of the Multi-Effect Distillation unit, with identification of the control volume is shown.

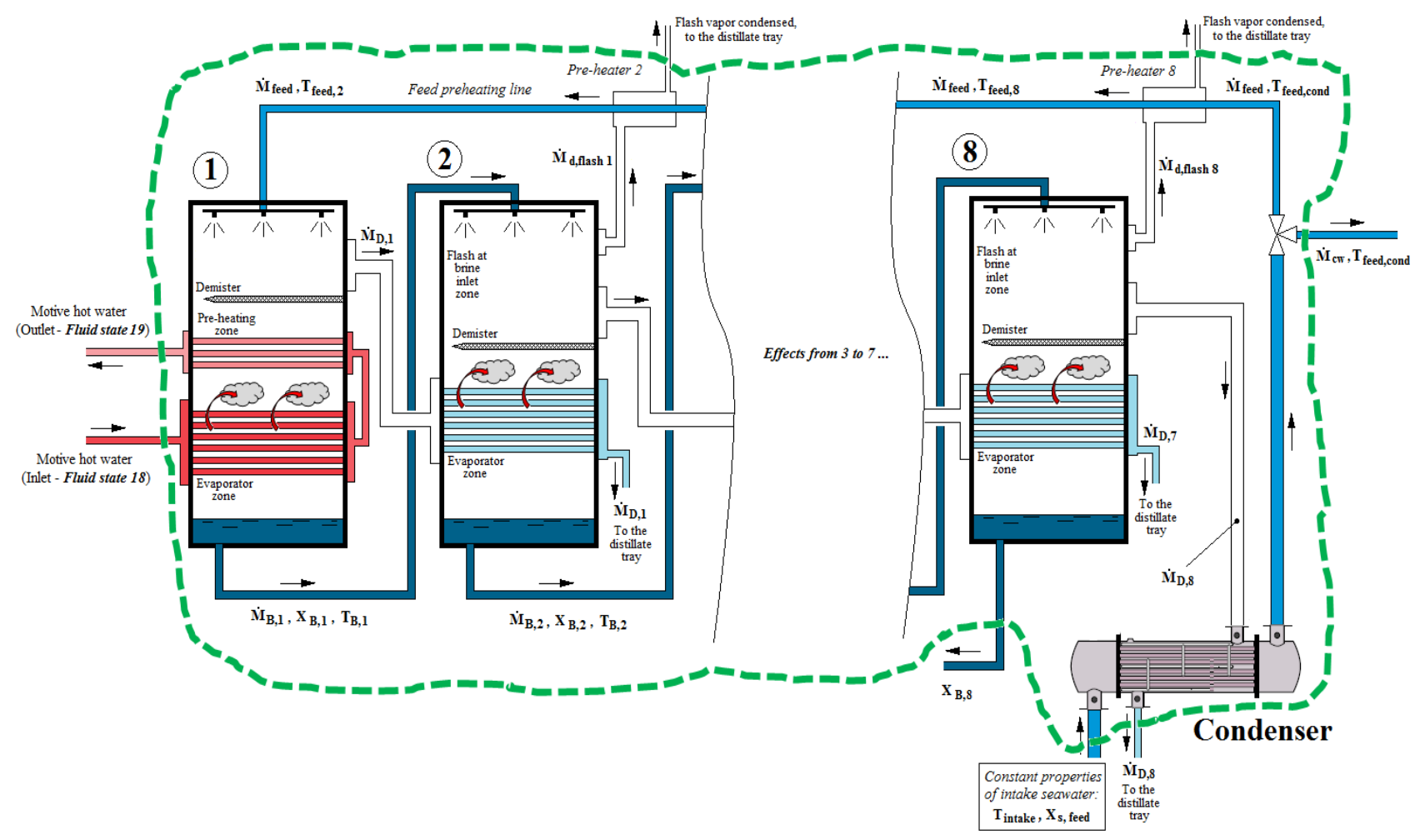

Figure 2. Schematic representation of the MED unit.

Then, all the energy transfer processes, either at the effects from 1 to 8 , at the feed pre-heaters and at the down condenser, are included in the control volume and we may focus the attention on the limited number of material streams entering/exiting the volume:

- Motive hot water (i.e., the hot water that supplies heat to the MED unit) entering the 1st effect at conditions represented by thermodynamic state 18 (following the notation in Figure 1) and exiting at state 19. The motive hot water is not involved in any separation process, being then unnecessary to calculate its chemical exergy content that remains constant. The exergy released to the 1st effect is:

$$
\dot{E} x_{18}-\dot{E} x_{19}=\dot{m}_{18} \cdot c \cdot\left(T_{18}-T_{19}-T_{a} \ln \frac{T_{18}}{T_{19}}\right)
$$

Desalted water produced by two different phenomena: (a) evaporation occurring in the falling film heat exchanger located within each effect; (b) separation of a small amount of flash vapor whenever, for $i=2$ to 8 , the brine exiting the $i$-1th effect is introduced in the $i$ th effect in which a lower pressure (i.e., higher vacuum) reigns. The amount of fresh water produced (indicated as "stream 21 " in Figure 1) is then calculated as: 


$$
\dot{m}_{21}=\sum_{i=1}^{8} \dot{M}_{D, i}+\sum_{i=2}^{8} \dot{M}_{D, \text { flash } i}
$$

The thermal exergy associated with fresh water is not calculated, since the distillate collected in the tray finally comes into thermal equilibrium with the environment, with no useful scope. Then, the fresh water product is only associated with a chemical exergy flow exiting the control volume, and calculated by the following expression [57]:

$$
E x_{c, 21}=\omega_{t h, 0} \cdot N_{21}
$$

where $\omega_{\text {th, } 0}$ represents the theoretical minimum work of separation of pure water in case of null recovery ratio (i.e., null ratio between the fresh water and the feed water flow rates), measured in $\mathrm{kJ} / \mathrm{kmol}$ water, and $\mathrm{N}_{21}$ indicates the molar flow of fresh water (in $\mathrm{kmol} / \mathrm{s}$ ); these terms are respectively calculated by:

$$
\begin{gathered}
\omega_{\mathrm{th}, 0}=\phi \cdot \mathrm{R}_{\text {universal }} \cdot \mathrm{T}_{0} \cdot \mathrm{X}_{\mathrm{s}, \text { feed }} \\
\dot{N}_{21}=\frac{m_{21}}{M M_{\text {water }}}
\end{gathered}
$$

with: $M M_{\text {water: }}$ molar weight of water equal to $18 \mathrm{~kg} / \mathrm{kmol} ; \phi$ : Dissociation factor (assumed equal to 2 for $\mathrm{NaCl}) ; R_{\text {universal }}$ : Universal constant of gases $(\mathrm{kJ} / \mathrm{kmol} \mathrm{K}) ; X_{s, f e e d}$ : Molar concentration of salts in the seawater. Assuming a 38,000 ppm for the salinity of the feed (which is a reasonable figure for the Mediterranean area) a molar concentration equal to 0.0116 is obtained.

- The cooling water that absorbs at the condenser any surplus heat released from the condensing distillate flow $M_{D, 8}$ that cannot be used to pre-heat the feed. The cooling flow is discarded back to the sea at a temperature $\mathrm{T}_{\text {feed,cond }}$ usually some degrees higher than the intake seawater temperature. Although trivial, calculating the thermal exergy content of this stream is not needed since this exergy flow exiting the boundary volume represents a net loss that, even occurring outside the control volume, can be included in the total exergy balance of the MED unit as any other exergy destruction occurring inside the volume;

- The high salt concentration brine discarded at the last effect, whose chemical exergy flow can be calculated as follows [57].

$$
\dot{E} x_{B, 8}=\left(\omega_{t h, R}-\omega_{t h, 0}\right) \cdot \dot{N}_{21}
$$

where $\omega_{\text {th,o }}$ has been obtained by Equation (13) and $\omega_{\mathrm{th}, \mathrm{R}}$ represents the theoretical minimum work of separation of pure water for finite water recovery ratios, calculated as follows:

$$
\omega_{\text {th }, R}=\phi \cdot \mathrm{R}_{\text {universal }} \cdot \mathrm{T}_{0} \cdot \mathrm{X}_{\mathrm{s}, \text { feed }} \cdot \frac{X_{s, B, 8}}{X_{s, B, 8}-\mathrm{X}_{\mathrm{s}, \text { feed }}} \cdot \ln \frac{X_{s, B, 8}}{\mathrm{X}_{\mathrm{s}, \text { feed }}}
$$

However, the term $E x_{B, 8}$ will not be explicitly included in the exergy destruction and efficiency expressions since, as said above for the thermal exergy of the cooling water, also the chemical exergy of the concentrated brine is lost immediately outside the MED system's boundary due to rejection back to sea. 
The exergy destruction rate for the whole MED, calculated including all the exergy destructions occurring inside and immediately outside the boundaries of the control volume due to the spontaneous evolution into equilibrium with the environment of the rejected stream, is given by:

$$
\dot{E} x_{d, M E D}=\dot{E} x_{18}-\dot{E} x_{19}-E x_{c, 21}
$$

and the exergy efficiency of the MED section can be expressed as:

$$
\eta_{e x, \mathrm{MED}}=\frac{E x_{c, 21}}{\left(\dot{E} x_{18}-\dot{E} x_{19}\right)+\dot{W}_{\mathrm{MED}}}
$$

where $W_{\text {MED }}$ is the power consumption by the MED section and $E x_{c, 21}$ is the chemical exergy flow calculated by Equation (12).

\subsubsection{Heat Exchangers}

The exergy balance of heat exchangers can be written simply considering, inlet and exiting streams. As an example, using HE1 as reference, the exergy destruction is:

$$
\dot{E} x_{d, \mathrm{HE} 1}=\dot{E} x_{2}+\dot{E} x_{8}-\dot{E} x_{9}-\dot{E} x_{3}
$$

Similar balances can be used for calculating exergy destructions of HE2 and HE3. Conversely, the exergy efficiency depends on the scope of the heat exchanger (cooling or heating). Thus, the following formulations are used:

$$
\begin{gathered}
\eta_{e x, \mathrm{HE} 1}=\frac{\left(\dot{E} x_{9}-\dot{E} x_{8}\right)}{\left(\dot{E} x_{2}-\dot{E} x_{3}\right)} \\
\eta_{e x, \mathrm{HE} 2}=\frac{\left(\dot{E} x_{28}-\dot{E} x_{27}\right)}{\left(\dot{E} x_{13}-\dot{E} x_{14}\right)}
\end{gathered}
$$

Finally, it worth noting that in case of HE3 an exergy efficiency cannot be defined. In fact, from the exergy point of view this is a dissipative component. Thus, no useful exergy product can be identified.

\subsubsection{Tanks}

The exergy balance of tank must also consider the exergy stored in the systems. As an example, using TK1 as reference, the exergy destruction is:

$$
\dot{E} x_{d, \mathrm{TK} 1}=\dot{E} x_{4}+\dot{E} x_{15}-\dot{E} x_{10}-\dot{E} x_{6}-c \frac{\partial\left(T_{T K 1}-T_{a}-T_{a} \ln \frac{T_{\mathrm{TK} 1}}{T a}\right)}{\partial \vartheta}
$$

It is worth noting that the previous equation considers the tank average temperature $T_{T K 1}$. In fact, the tank under investigation is subject to thermal stratification, determining a significant vertical temperature gradient which is calculated by a detailed energy model [21] considering the vertical tank 
divided in $n$ fully mixed nodes. Therefore, the above mentioned exergy balance should be written separately for each one of the $\mathrm{n}$ nodes. These long calculations will allow one to evaluate the local exergy destruction in each node of the tank. However, the overall exergy destruction in the tank can be more easily calculated with respect to the sole tank average temperature. In the case of tank, no specific exergy product can be considered. Therefore, the definition of the exergy efficiency is meaningful.

\subsection{6. $\mathrm{ACH}$}

The calculation of the exergy destruction rate is given by:

$$
\dot{E} x_{d, \mathrm{ACH}}=\dot{E} x_{11}+\dot{E} x_{25}+\dot{E} x_{22}-\dot{E} x_{12}-\dot{E} x_{23}-\dot{E} x_{24}
$$

The exergy efficiency is given by:

$$
\eta_{e x, \mathrm{ACH}}=\frac{\left(\dot{E} x_{23}-\dot{E} x_{22}\right)}{\left(\dot{E} x_{11}-\dot{E} x_{12}\right)}
$$

\subsubsection{RPS}

Finally, the equation for the global exergy efficiency, ratio between exergy product and fuel, of the RPS is given by:

$$
\eta_{e x}=\frac{\left(\dot{W}_{C P V T}+E x_{c, 21}+\Delta \dot{E} x_{U S E R}\right)}{\left(\dot{E} x_{\text {sun }}+\dot{E} x_{\text {biomass }}\right)}
$$

where $\Delta \dot{E} x_{U S E R}$ is the physical exergy variation, depending on the inlet and outlet temperature from the generic user.

\subsection{Economic Model}

In order to assess the most convenient configuration and operation of the plant (number and sizes of units, flow rates etc.) considering all simulated ones, two economic objective functions were defined.

The first objective function represents the annual operation cost $C_{o p}$, Equation (26), associated to operation of the plant that considers: (i) the annual capital cost of the all components of the plant $J_{\text {tot, year }}$, Equation (27); (ii) the annual saving in terms of operating costs achieved by the RPS respect the reference system, $\Delta C_{o p}$. This term is strictly related to the savings of electrical, thermal, cooling energy, to the production of desalted water and to the operation cost for the auxiliary heater $\mathrm{AH}$ (the wood chip cost); (iii) the public funding for the annual energy and water production, FUN; (iv) the environmental aspect in terms of the economic gain obtained by the emission trading certificates, considering the $\mathrm{CO}_{2}$ annual emissions savings $B C$, Equation (28). This last term is calculated considering the obtained saving of electrical and thermal energy during the year. Therefore, considering the sum over all the time-steps, the objective functions $C_{o p}, J_{\text {tot,year }}$ and $B C$ are: 


$$
\begin{gathered}
C_{o p}=\left(J_{\text {tot, year }}-\Delta C_{o p}-F U N-B C\right) \\
J_{\text {tot, year }}=\frac{J_{t o t}}{A F} \\
B C=\sum_{i} F_{e l} \cdot c_{C O_{2}} \cdot \frac{\left(\mathrm{E}_{\mathrm{el}, \mathrm{CPVT}}-\mathrm{E}_{\mathrm{el}, \mathrm{aux}}\right)_{i}}{\eta_{e l, t}}+F_{N G} \cdot c_{C O_{2}} \cdot\left(\mathrm{Q}_{h, i}+\mathrm{Q}_{D H W, i}\right)
\end{gathered}
$$

The capital costs of all the components of the system are calculated on the basis of the cost figures presented in reference [21]:

$$
\begin{gathered}
J_{C P V T}=600 \cdot A_{C P V T} \\
J_{A C H}=10^{-5} \cdot P_{A C H}{ }^{3}-0.0393 \cdot P_{A C H}{ }^{2}+244.53 \cdot P_{A C H}{ }^{3}+95494 \\
\mathrm{~J}_{\mathrm{TK}}=494.9+0.808 \cdot \mathrm{V}_{\mathrm{TK}} \\
J_{\text {pump }}=1.08 \cdot\left(-0.00000002 \cdot Q_{\text {pump }}{ }^{2}+0.0285 \cdot Q_{\text {pump }}+388.14\right) \\
J_{H E}=150 \cdot\left(\frac{A_{H E}}{0.093}\right)^{0.78} \\
\mathrm{~J}_{\mathrm{MED}}=0.5 \cdot\left[800 \cdot\left(\dot{M}_{D, \text { total }} \cdot 3.6 \cdot 24\right)+\mathrm{c} \cdot\left(\mathrm{A}_{\text {total }}\right)^{\gamma}\right]
\end{gathered}
$$

Reference [21] also includes all the data and parameters required to calculate investment and O\&M cost figures. In Equation (26), the terms with the sign "-" represents the economic gain, the term with the sign "+" the cost. Therefore, in order to maximize the economic profitability of the RPS, and consequently minimize the operation cost for the auxiliary heater and the capital costs for all components, the annual operation cost objective function, $C_{o p}$, must be minimized. The used feed-in tariffs for $F U N$ are: $0.45 € / \mathrm{kWh}$ for electric energy, $0.20 € / \mathrm{kWh}$ for thermal and cooling energy and $1.0 € / \mathrm{m}^{3}$ for desalinated water. The equations and the used values for assessing the terms $J_{\text {tot }}$ and $\Delta C_{o p}$, are available in reference [14]. In Equation (27) the Annuity Factor $(A F)$ is calculated equal to 12.5 years, considering a discount rate equal to $5 \%$ and a time horizon of 20 years. In Equation (28) $F_{N G}$ is the emission factor of natural gas in $\mathrm{kg} \mathrm{CO}_{2}$ equivalent per $\mathrm{kWh}_{\mathrm{t}}, F_{e l}$ is the emission factor of electrical energy, respectively, assumed equal to $0.20 \mathrm{kgCO}_{2} / \mathrm{kWh}_{\mathrm{t}}$ and $0.48 \mathrm{kgCO} 2 / \mathrm{kWh}_{\mathrm{el}} ; c_{\mathrm{CO}_{2}}$ is the economic value assumed for the $\mathrm{CO}_{2}$ emission savings, equal to $0.001 € / \mathrm{kgCO}_{2}$. The Profit Index $(P I)$, defined by Equation (35), is selected as the second objective function. $N P V$ is the Net Present Value, Equation (36), also considers the emission trading certificates, the incentives and the economic saving. The higher the PI values are, the best the economic profitability of the system. For this reason, the Profit Index objective function, $P I$, must be maximized:

$$
\begin{gathered}
P I=\frac{N P V}{J_{t o t}} \\
N P V=A F \cdot\left(B C+F U N+\Delta C_{o p}\right)-J_{t o t}
\end{gathered}
$$




\section{Results and Discussion}

\subsection{Exergy Analysis}

On the basis of the exergy model, briefly presented in the previous section, the simulation tool allows one to calculate all the components of the exergy balances (fuel, product and destroyed exergy) and the exergy performance parameters (exergy efficiency and efficiency defect) for the single components and for the system as a whole. Such parameters can be calculated on whatever time basis. In this section, for sake of clarity, results are integrated on daily basis. Such time scale allows one to analyze the variation of the parameters during the year and simultaneously the integration mitigates the unavoidable fluctuations occurring during the dynamic operation of the system. As mentioned before, the system under investigation was supposed to be located in Naples, in the South of Italy. Therefore, all the weather data (ambient temperature, humidity, solar radiation, wind velocity, etc.) are obtained from Meteonorm database for that location. According to this database, the average daily total radiation on horizontal is $4.18 \mathrm{kWh} / \mathrm{m}^{2}$ day. Such reading dramatically varies during the year, ranging from 0.45 to $8.7 \mathrm{kWh} / \mathrm{m}^{2}$ day. As discussed in reference [21], the system is assumed to be used as a retrofit/repowering of an existing and larger heating and cooling system. Therefore, all the cooling and heating energy produced by the RPS is assumed to be consumed by the end user. Additional data regarding system design parameters and design variables are diffusely provided in reference [21].

In particular, Figure 3 shows the exergy inputs for the system (fuels), namely: solar energy, biomass used by the AH and electrical energy consumed by the auxiliary devices. Here, it is clearly show that the exergy flow related to the auxiliary electrical devices is marginal with respect to the remaining ones. As expected, it is also clearly shown that the solar exergy varies proportionally to the available solar radiation, becoming extremely high during the hottest summer days. During the summer, the magnitude of solar exergy is often higher than the one related to the biomass. Conversely, in winter this trend changes. This is due to the fact that the running time of the AH and MED is strictly related to the daylight time, which dramatically decreases in winter.

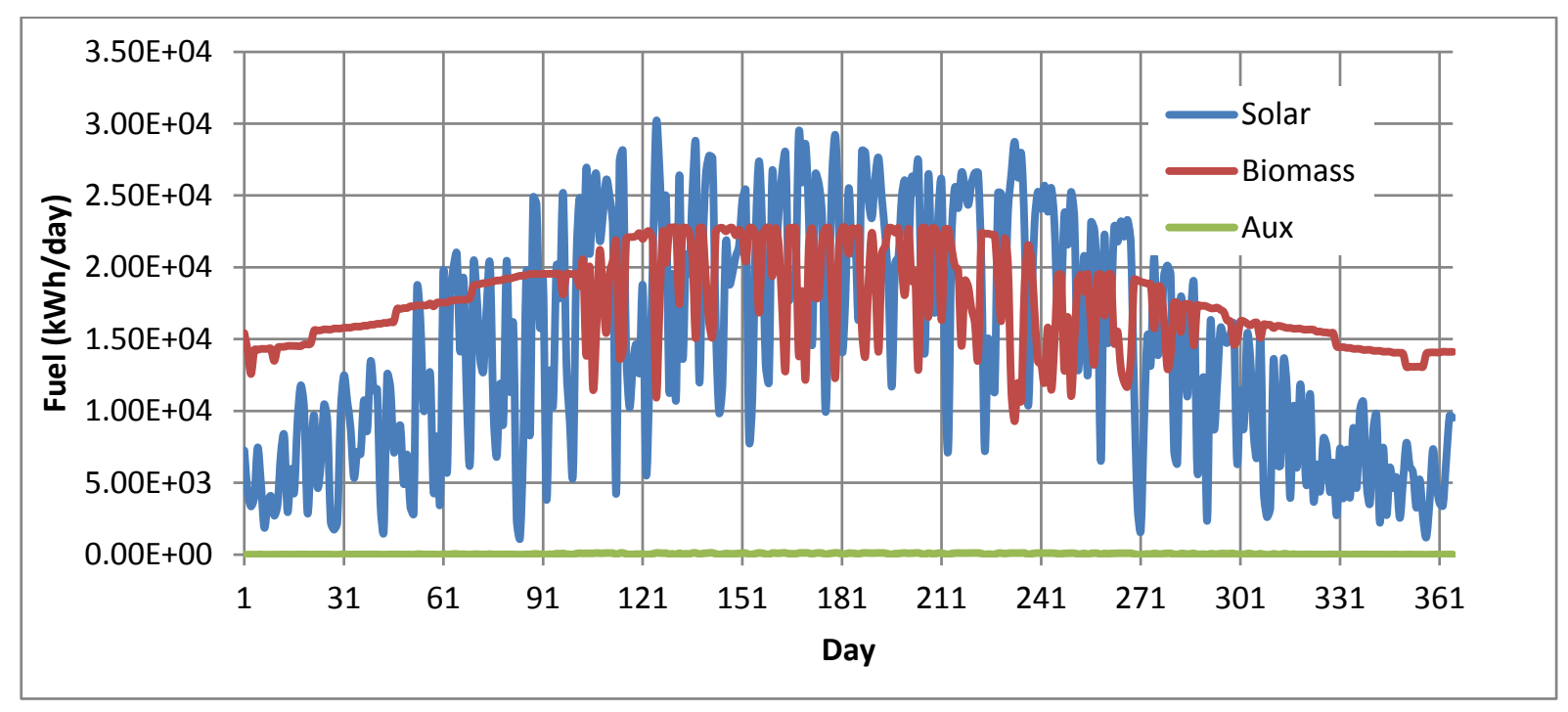

Figure 3. Daily exergy fuel. 
As a consequence, a lower amount of biomass is demanded in winter, determining the trend shown in Figure 3. Figure 4 shows the exergy outputs (products) of the system.

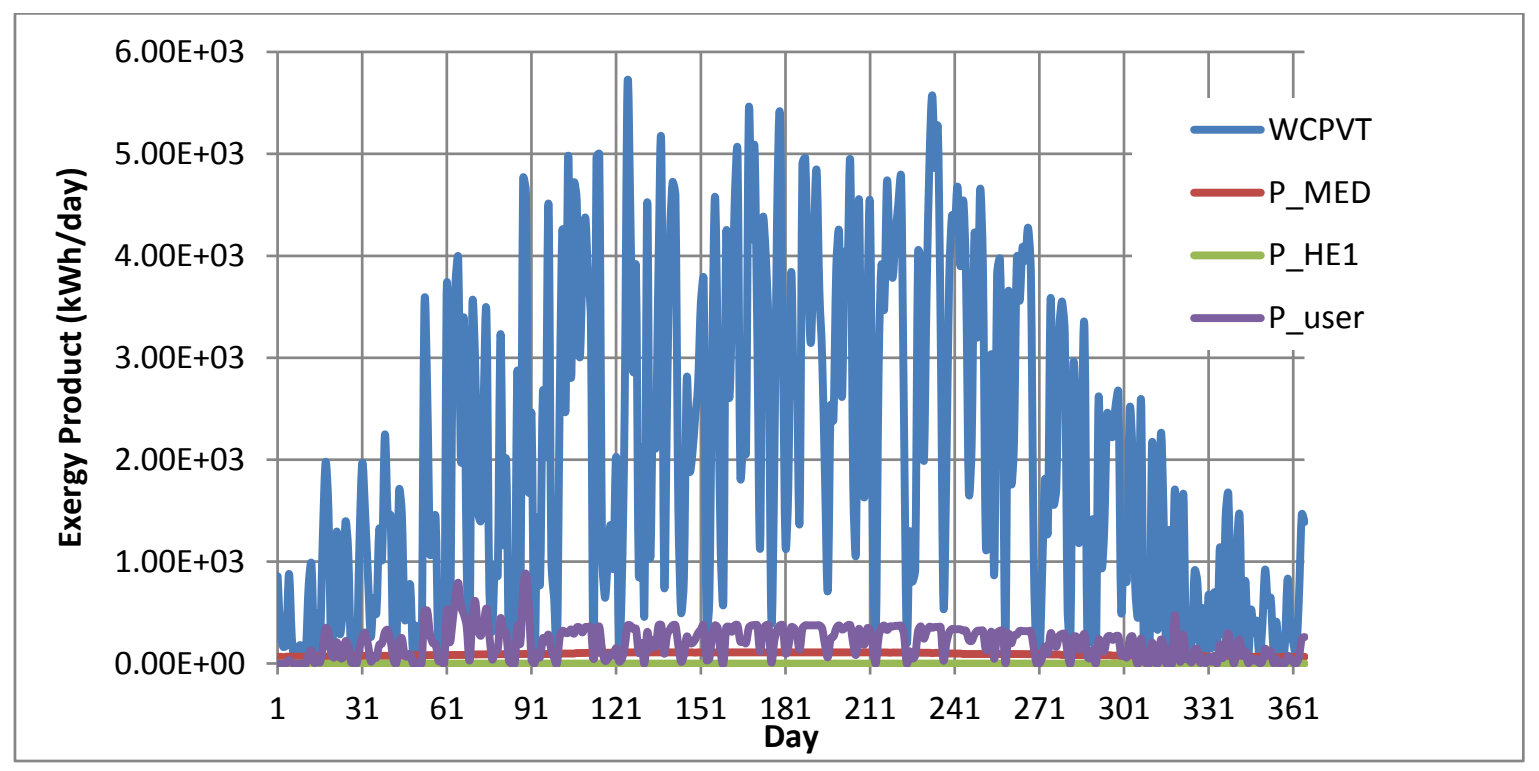

Figure 4. Daily exergy product.

As expected, the exergy flow related to the CPVT electrical production is strictly dependent on the available solar exergy input. This exergy product is dominant over the other ones. This result is not trivial. In fact, from the energy point of view, this electrical production is much lower than the thermal and cooling ones [21]. However, from the exergy point of view, the "quality" of such thermal and cooling energy is poor being the temperature of the fluid very close to the environmental one. Thus, this important result suggests to pay much more attention to the CPVT electrical production than to the thermal/cooling one. Figure 4 also shows that the exergy product, related to the produced desalted water, is much lower than the electrical, thermal and cooling ones. This product also increases during the summer as a consequence of the enhanced MED capacity. Finally, HE1 exergy product is null since that heat exchanger is never activated. Figures 3 and 4 show that, during the summer, a significant increase of both exergy fuels and products are achieved. This is due to the higher availability of solar radiation which determines an increase of the RPS daily operating time. As expected, the higher the exergy product, the higher the exergy destruction in the RPS, as shown in Figure 5.

Here, it is also clear that the highest exergy destruction is achieved in the auxiliary heater (AH). A significant contribution is also given by the solar field, which in the summer shows irreversibilities comparable with the $\mathrm{AH}$ ones. Conversely, exergy destructions in all the remaining components are orders of magnitude lower. Finally Figure 6 shows the exergy efficiencies of the main components and of the RPS system as a whole.

ACH exergy efficiency oscillates between $30 \%$ and 35\%. CPVT exergy efficiency is very low, in accordance with similar results available in literature, oscillating between $5 \%$ in the coldest winter days up to $27 \%$ in summer. MED and RPS exergy efficiencies are very stable around $5.5 \%$ and $4 \%$, respectively.

The overall result of this analysis suggests that the system exergy efficiency is poor. Although the system is based on renewable energy source, their exergy utilization is very difficult. In fact, solar 
energy use determines large irreversibilities due to the high temperature difference between the sun the operating fluid. Similarly, biomass is used in a conventional heater where the exergy efficiency is poor since the temperature of the heated fluid is low (around 75\%).

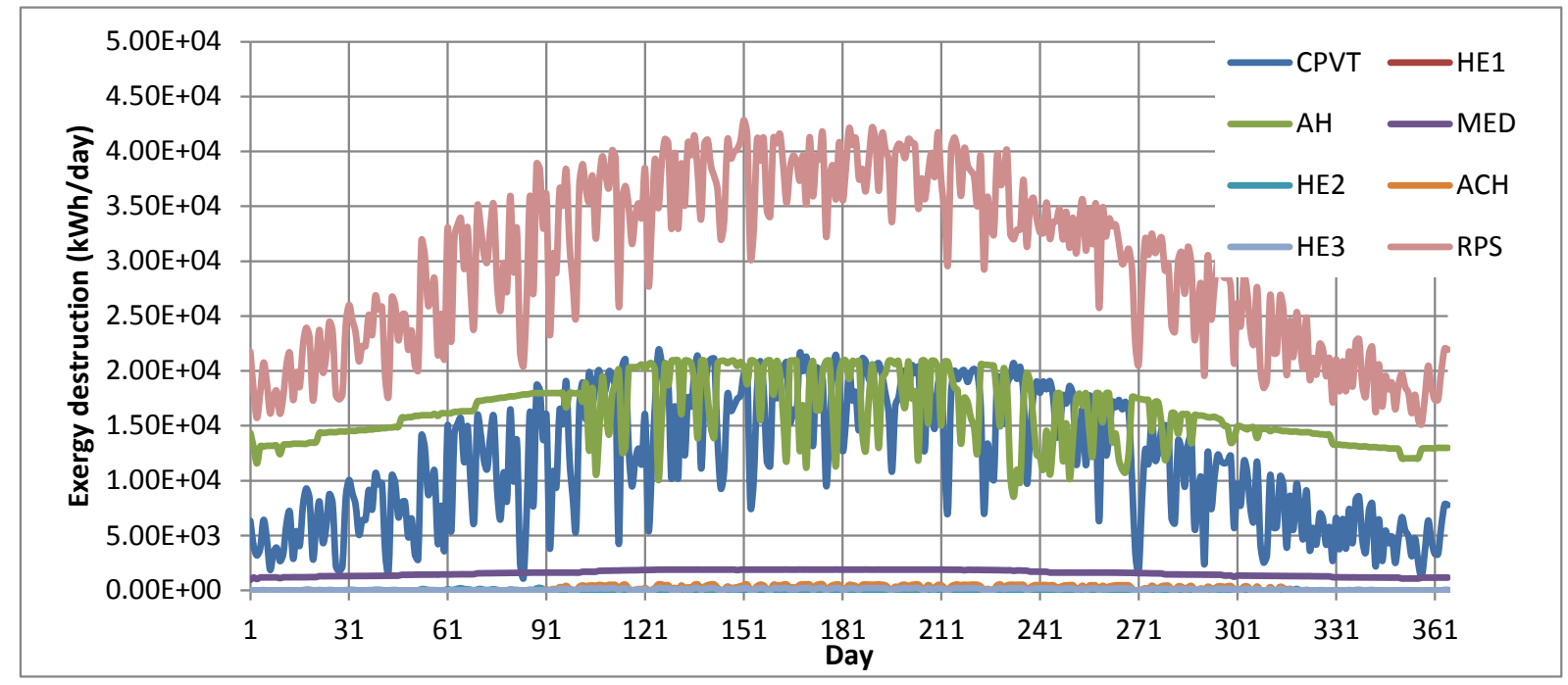

Figure 5. Daily exergy destruction.

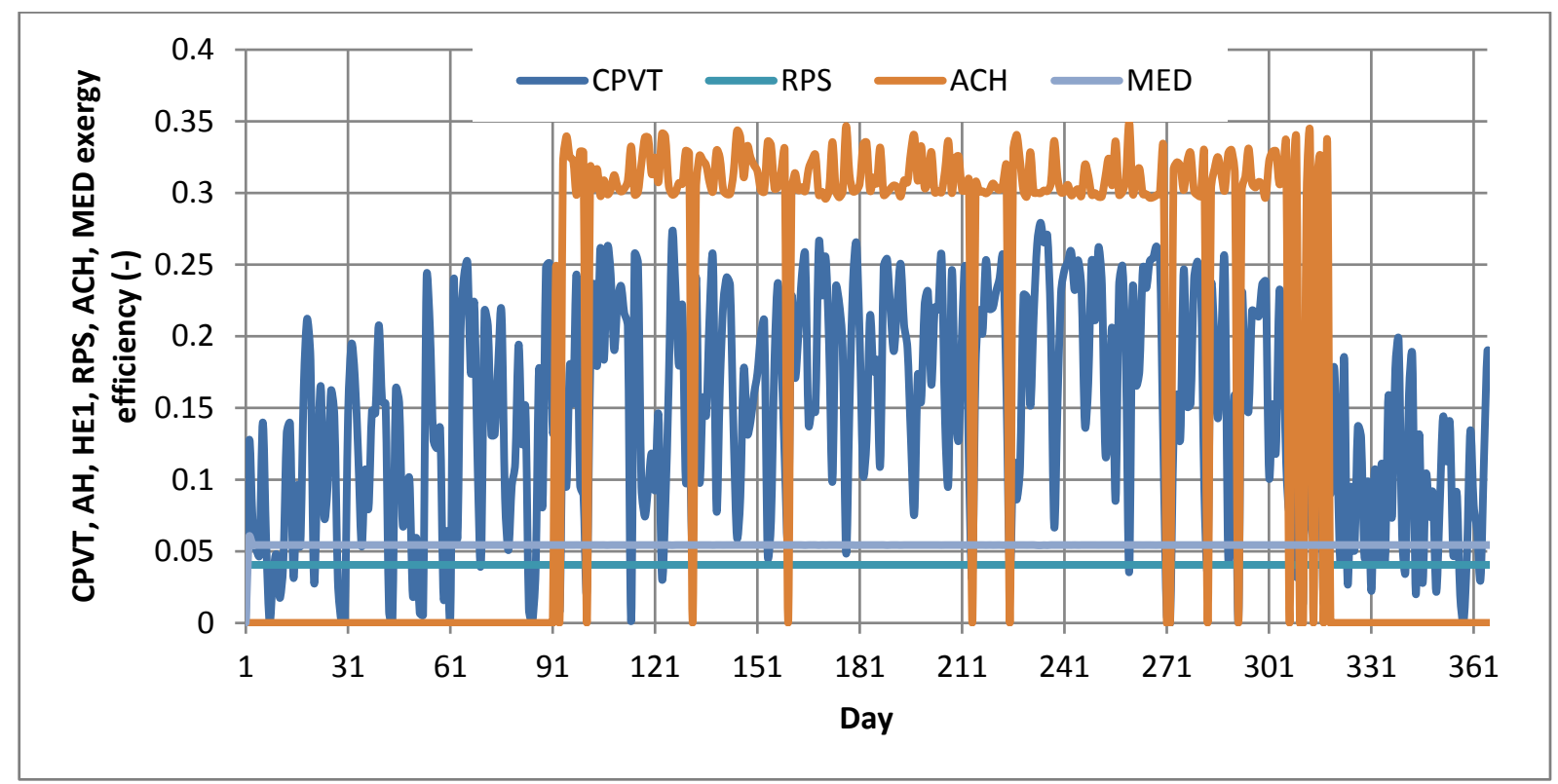

Figure 6. Daily exergy efficiency.

\subsection{Exergoenviromental and Economic Optimizations}

The previous analysis shows that the system may be significantly optimized from exergy (and consequently also from thermoeconomic) point of view. Therefore, an optimization procedure for determining the value of the most important design parameters was carried out.

In the present paper, the computer Design of Experiment (DoE) analysis [51] was performed. By such technique, the set of synthesis/design parameters for optimizing the system exergy, environmental and economic performance was detected. In general this technique is widely adopted 
for industrial and academic purposes in order to maximize (or minimize) a selected objective function. In particular, the DoE allows one to: (i) analyse the effects of the main design parameters on the considered objective function; (ii) create an analytic model of the selected objective function in relation to the system design variables; (iii) plot the optimum response surface, i.e., the graphical depiction of the assessed analytic function and (iv) perform an optimization procedure aiming at determining the optimal values of the design variables. In order to keep low the iteration number of the DoE procedure, statistical techniques should be adopted. For the industrial applications this reduction is strongly recommended for limiting the systems' design costs. A lower number of experiments are usually obtained adopting fractional factorial designs. In this paper, the optimization procedure is achieved replacing the conventional experimental campaign by computer simulations, carried out by the above described transient models. Such process is obtained by just a single repetition of each simulation experiment, since such simulated experiments are obviously not affected by any result variations (measurement errors) that conversely occur in the real experimental processes. Here, a full factorial design is utilized in order to improve the DoE results accuracy, suffering the only disadvantage of longer computational times. Therefore, the number of system design variables and the corresponding levels are chosen as a function of the maximum time selected for the computer simulation.

For the optimization procedure considered in this paper, the following four design variables are selected: (i) the number of PVT collectors ( $\mathrm{NSC}_{\mathrm{SC}}$; (ii) the number of MED effects ( $\mathrm{N}_{\mathrm{EFF}}$ ); (iii) TK1 volume per SC surface area (vTK1); (iv) P4 flow rate/NSC $\left(\mathrm{q}_{\mathrm{p} 4}\right)$. For all the considered variables, the number of levels is set equal to 4 and the corresponding values are reported in Table 1.

Table 1. Optimizing variables and corresponding levels.

\begin{tabular}{cccccc}
\hline Variable & Unit & Level 1 & Level 2 & Level 3 & Level 4 \\
\hline $\mathrm{N}_{\mathrm{SC}}$ & $(-)$ & 250 & 500 & 750 & 1000 \\
$\mathrm{~N}_{\mathrm{EFF}}$ & $(-)$ & 5 & 8 & 11 & 14 \\
$\mathrm{v}_{\mathrm{TK} 1}$ & $\mathrm{~L} / \mathrm{m}^{2}$ & 25 & 50 & 75 & 100 \\
$\mathrm{q}_{\mathrm{p} 4}$ & $\mathrm{~kg} / \mathrm{h}$ & 100 & 250 & 500 & 750 \\
\hline
\end{tabular}

For such considered operating conditions, 256 different simulations are required. Each simulation is referred to an entire year with a selected time-step of $0.04 \mathrm{~h}$. The resulting computational time was close to $20 \mathrm{~min}$ for simulation. Therefore, the overall optimization can be completed in about 4 days of continuous calculations. Alternative possible optimization techniques (requiring different runs for each selected objective functions) would require computational times one order of magnitude higher than. For evaluating the combined exergy, economic and environmental performance of the RPS, 4 objective functions are selected: (i) the overall destroyed exergy, Exd,total; (ii) the operating cost, $\mathrm{C}_{\mathrm{op}}$; (iii) the exergy efficiency of the system, $\eta_{\mathrm{ex}}$; (iv) the profit index, PI. For each possible combination of the considered design variables, such functions are calculated. For each objective function a fourth order interpolating function is defined. Usually such function is considered in order to: (i) assess the main effects of the selected variables on the system performance (i.e., a correlation between the selected objective function and the system considered design variables); (ii) draw the relative interaction plots (main effects curves parameterized as a function of the system design variables); (iii) obtain a system 
optimal response surface (i.e., an analytical relationship among the objective function and all the considered design variables).

\subsubsection{DoE: Main Effects Plots}

By the main effect plots the mean value of the selected objective function for each level of the considered design variable and the influence of each design parameter variation on the objective function are obtained. Figures 7-9 show the main effect plots for, respectively, Exd,total, $\mathrm{C}_{\mathrm{op}}$, PI and $\eta_{\mathrm{ex}}$. In Figure 7 the main effect plots for Exd,total are shown.

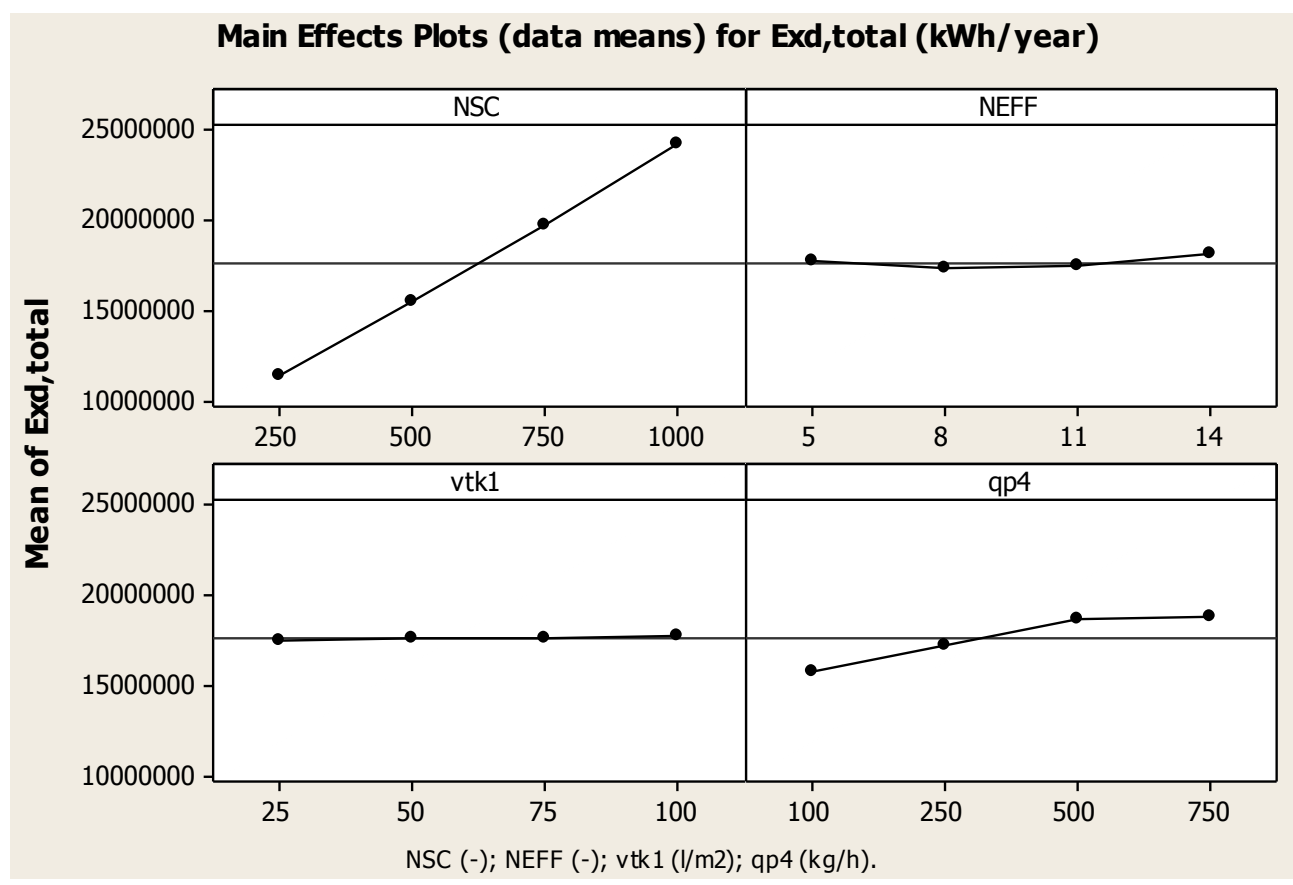

Figure 7. Main effects plots for Exd,total.

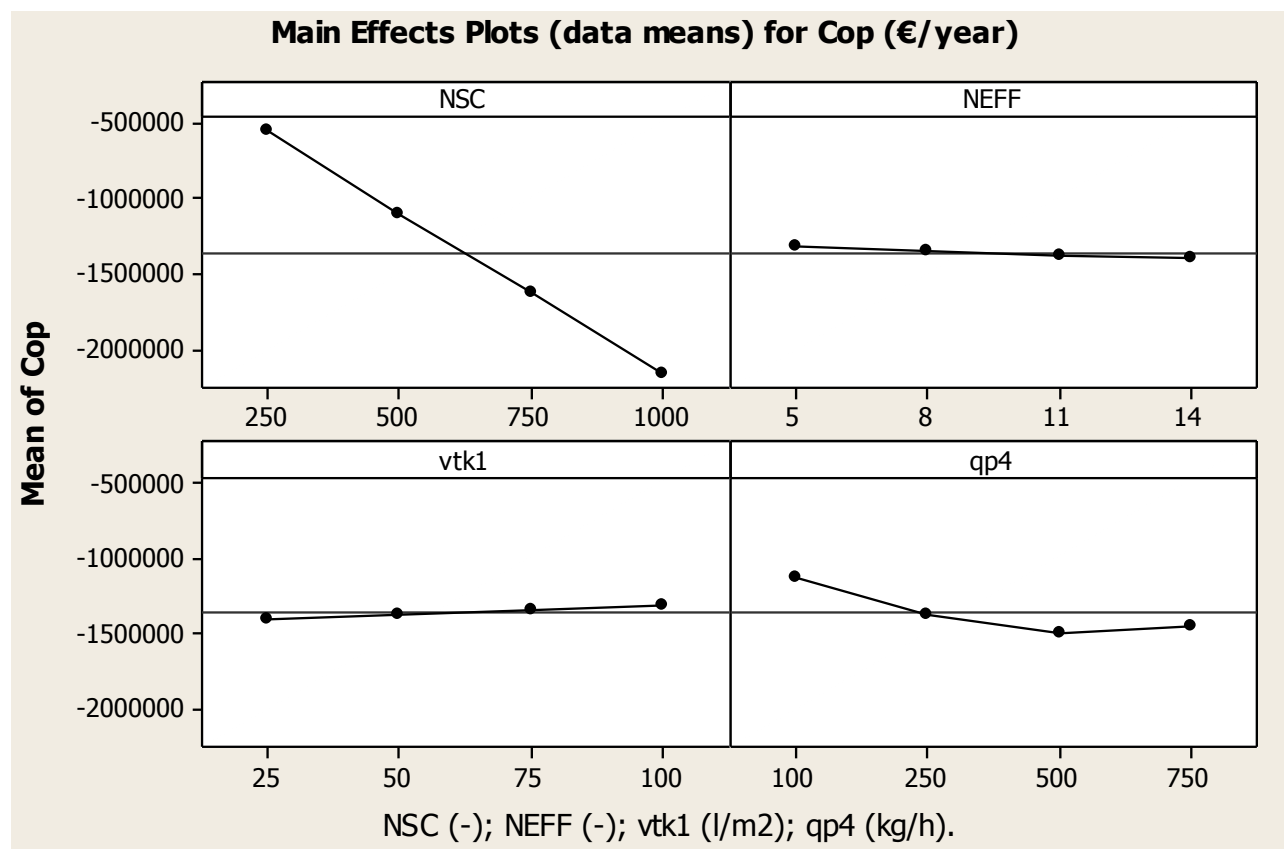

Figure 8. Main effects plots for $C_{o p}$. 


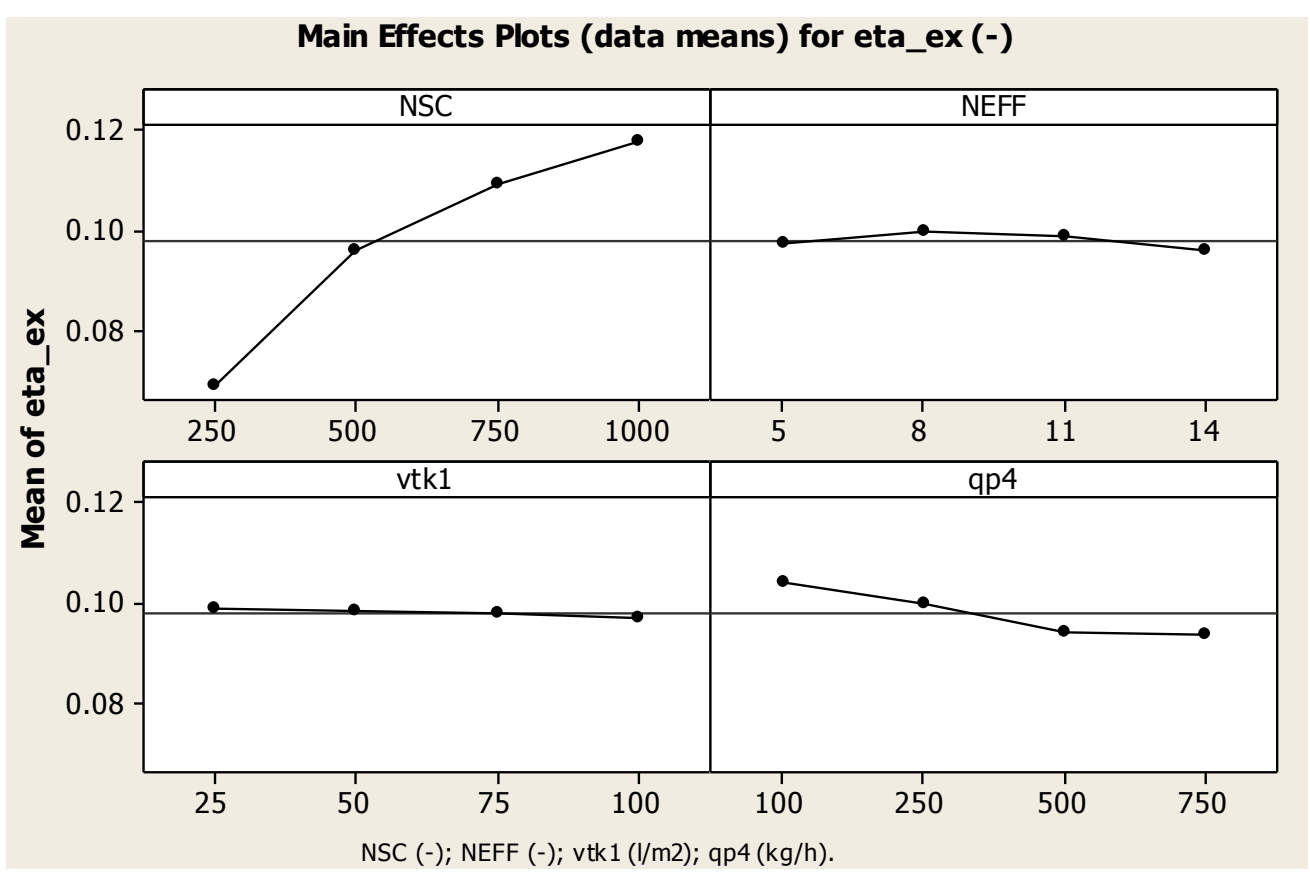

Figure 9. Main effects plots for $\eta_{\mathrm{ex}}$.

In particular, an increase of NSC involves a greater production of electric and thermal energy, but also an increase in the overall exergy destruction, Exd,total, basically due to the increased contribution of solar collectors. It is clearly shown that the most significant parameter for the Exd,total variation is NSC. An increase of NEFF from 5 to 14 does not significantly affect the trend of Exd,total. In fact, an increase of the number of effects only determines a greater production of desalted water, whereas the heat demand remains almost constant. This circumstance, in combination with the low MED efficiency defect, determines the trend shown in the figure. In the same figure, it is shown that an increase of the specific tank volume, VTK1, does not affect the Exd,total, that it is almost constant in all cases. This result suggests that an increase of the tank volume only determines a slight increase of exergy destruction, due to higher thermal losses occurring in larger tanks. An increase of $\mathrm{q}_{\mathrm{p} 4}$ slightly affects the Exd,total: in fact, such parameter ( $\mathrm{P} 4$ flow rate/NSC) defines the ratio between $\mathrm{ACH}$ (or $\mathrm{HE}$ ) capacity and that of the solar field. Therefore, the higher $\mathrm{q}_{\mathrm{p}}$, the higher the amount of thermal/cooling energy delivered to end users.

Consequently, an increase of such exergy product also determines an increase of the exergy destruction. Such trend is not linear. In fact, in case of ACH and HE large capacities, at constant solar field size, the exergy product remains almost constant since only a reduction of $\mathrm{ACH}$ and $\mathrm{HE}$ operating time is achieved. In Figure 8 the main effects plots for $\mathrm{C}_{\mathrm{op}}$ are shown.

$C_{o p}$ is defined as the difference between costs and incomes. Therefore, lower, and eventually negative values of such parameter, indicate a higher profitability of the system. Once again, Nsc is the most important parameter. In fact, the capacities of all components depend on the number of collectors included in the solar field. Obviously, when Nsc varies from 250 to 1000, the global capital cost proportionally increases. Simultaneously, a higher electrical and thermal production is achieved. Such increase determines a growth of annual revenues (public funding, economic annual saving, emission trading certificates) higher than the annual capital cost of the system. The overall result is a positive reduction of the objective function $C_{o p}$. Similarly, an increase of $\mathrm{N}_{\mathrm{EFF}}$ determines both a higher capital 
cost and a larger production of desalinated water: such effect is dominant over the higher system capital cost, determining a decrease of $C_{o p}$. However, such decrease is not particularly sharp, as shown in Figure 8. Conversely, an increase of VTK1 determines an increase of $C_{o p}$. In fact, larger tanks are not profitable, due to the higher capital costs and to the higher thermal losses. Finally, an increase of $\mathrm{q}_{\mathrm{p} 4}$ determines a non-monotonic trend of $C_{o p}$. In fact, this parameter affects $\mathrm{HE}$ and $\mathrm{ACH}$ capacities, as discussed above. Consequently, an optimum for $\mathrm{q}_{\mathrm{p} 4}$ is found around $500 \mathrm{~kg} / \mathrm{h}$, corresponding to a $\mathrm{ACH}$ cooling capacity of $2.9 \mathrm{~kW}$ per unit solar collector. In Figure 9 the main effect plots for $\eta_{\mathrm{ex}}$ are shown.

According to the trend of Exd,total, $\eta_{\mathrm{ex}}$ is particularly sensitive to NSC. In particular, the exergy efficiency increases in case of larger solar fields. This is due to the fact that CPVT exergy efficiency is higher than that of the Auxiliary Heater (AH). Therefore, an increase of the solar field area induces an increase of the CPVT efficiency defect and a decrease of the AH efficiency defect, resulting in an overall improvement of the RPS exergy efficiency. Conversely, NEFF, vTK1, and $\mathrm{q}_{\mathrm{p} 4}$ do not significantly affect $\eta_{\mathrm{ex}}$, which is close to 0.10 in all cases. A parametric analysis has been carried out in order to analyze the effects of the variability of some of the main design parameters on the objective function selected as representative of the efficiency and economic/environmental feasibility of the RPS. The interaction plots were obtained by fixing three of the design variables and varying the fourth one, for each RPS layout, so that the separate influence of each design parameter variation on the objective function is found out. For sake of brevity, such plots are not reported, but the corresponding information is provided by the contour plots of the optimal response surface reported in the following figures.

\subsubsection{DoE: Contour Plots of the Optimal Response Surface}

In Figures 10-12 the contour plots of the optimal response surface are displayed for $\mathrm{C}_{\mathrm{op}}$, Exd,total, and $\eta_{\mathrm{ex}}$, respectively. Each figure consists of six subplots, including all the possible combinations between the four considered design values. Each subplot was usually referred to the product of the two independent variables under consideration. So, for each plot two design variables were considered at the same time, whereas all the remaining variables were kept constant at their optimal values. Such values are reported on the right side of each figure. In Figure 10, the $C_{o p}$ response surface graph is displayed.

Here, it is clearly shown that the system performance improves when the maximum allowable number of CPVT is considered. A minimum of the objective function is also found for $\mathrm{q}_{\mathrm{p} 4}$, slightly higher than $500 \mathrm{~kg} / \mathrm{h}$. Figure 11 shows the contour plots of Exd,total. Here, the $\mathrm{vt}_{\mathrm{k} 1} * \mathrm{~N}_{\mathrm{EFF}}, \mathrm{q}_{\mathrm{p} 4} * \mathrm{~N}_{\mathrm{EFF}}$, $\mathrm{q}_{\mathrm{p}}{ }^{*} \mathrm{v}_{\mathrm{tk} 1}$ contour plots show the lowest gradients, particularly for the $\mathrm{vt}_{\mathrm{k} 1} * \mathrm{~N}_{\mathrm{EFF}}$ combination. Otherwise, the first row shows how dramatically $\mathrm{N}_{\mathrm{SC}}$ affects the overall system exergy destruction, Exd,total. In Figure 12 the contour plots of $\eta_{\mathrm{ex}}$ are reported.

$\mathrm{vt}_{\mathrm{k} 1} * \mathrm{~N}_{\mathrm{EFF}}, \mathrm{q}_{\mathrm{p} 4} * \mathrm{~N}_{\mathrm{EFF}}, \mathrm{q}_{\mathrm{p}} *^{*} \mathrm{v}_{\mathrm{tk} 1}$ combinations contour plots show the lowest gradients, particularly for $\mathrm{q}_{\mathrm{p} 4} * \mathrm{~N}_{\mathrm{EFF}}$ and $\mathrm{q}_{\mathrm{p}} * \mathrm{v}_{\mathrm{tk} 1}$ combinations. It is also clear that the higher the values of $\mathrm{N}_{\mathrm{SC}}$, the greater the $\eta_{\mathrm{ex}}$ $\left(>12 \%\right.$, dark green area). $\eta_{\mathrm{ex}}$ is maximized when $\mathrm{N}_{\mathrm{SC}}$ is greater than 750 and $\mathrm{q}_{\mathrm{p} 4}$ lower than $250 \mathrm{~kg} / \mathrm{h}$.

In summary, all the results shown by the analysis of the response surface show the same general trends obtained by the main effects plots. However, the analysis of the response surface is also useful to detect the optimal configuration for all the combinations of the design parameters. 


\section{Contour Plots of Cop (€/year)}
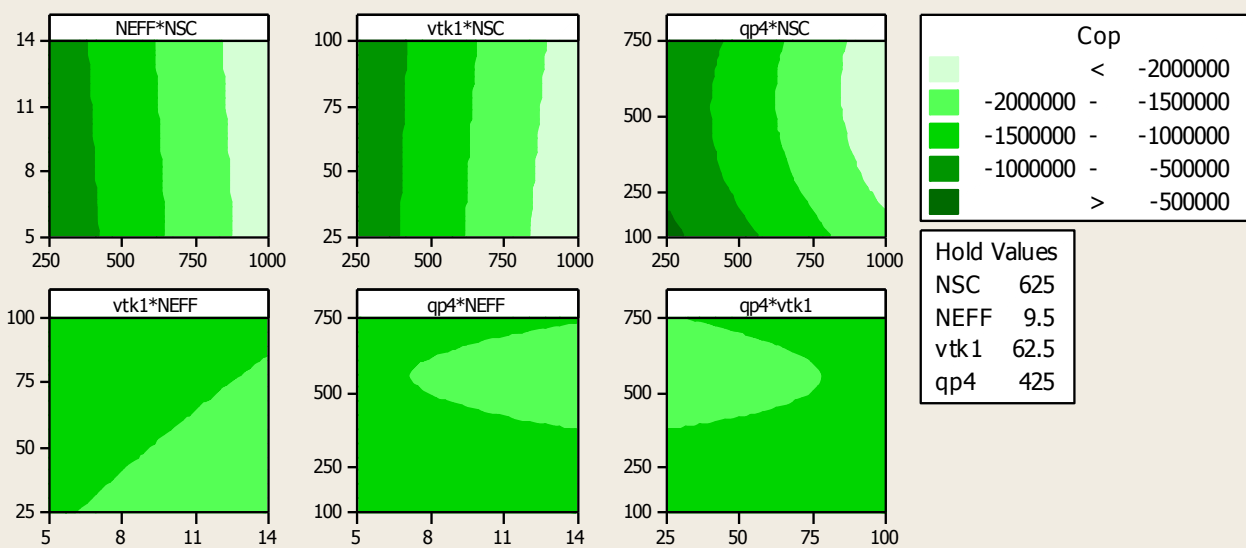

\begin{tabular}{|lr|}
\hline \multicolumn{2}{|l|}{ Hold Values } \\
NSC & 625 \\
NEFF & 9.5 \\
vtk1 & 62.5 \\
qp4 & 425 \\
\hline
\end{tabular}

$\operatorname{NSC}(-) ; \operatorname{NEFF}(-) ;$ vtk1 (l/m2); qp4 (kg/h).

Figure 10. Contour plots of $C_{o p}$.

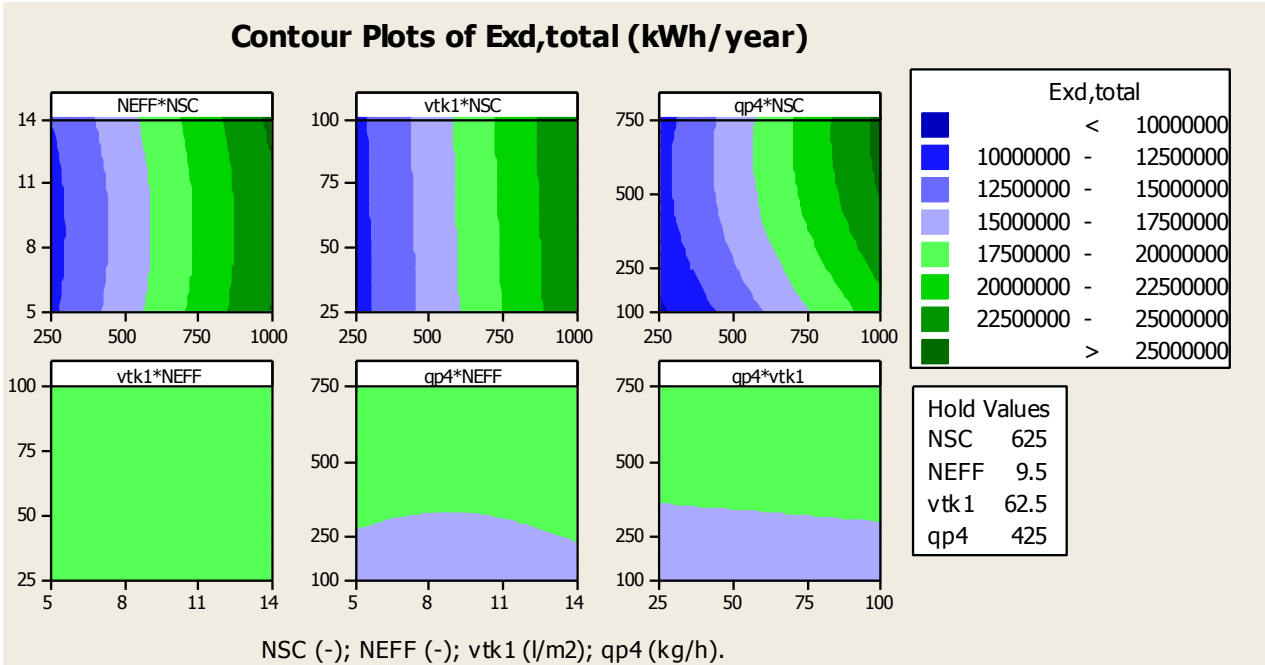

Figure 11. Contour plots of Exd,total.

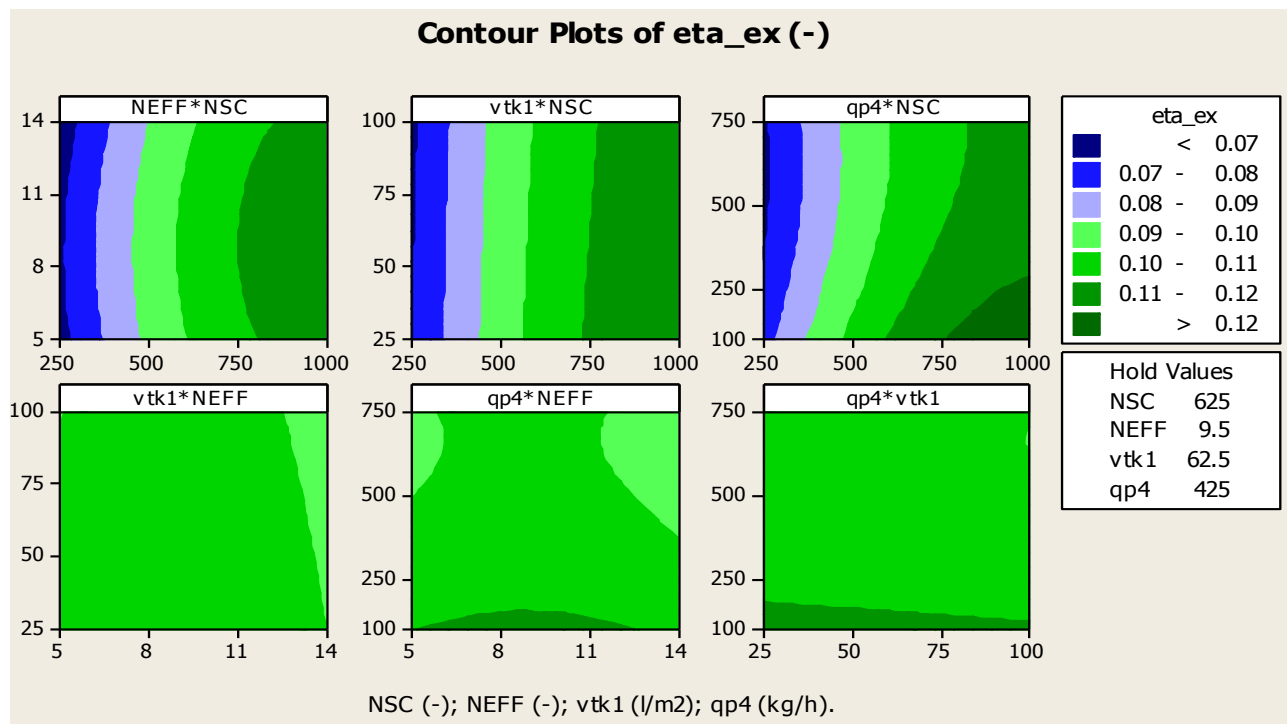

Figure 12. Contour plots of $\eta_{\text {ex. }}$ 


\subsubsection{DoE: Optimization}

The results of the analysis of the optimum response surface can be further refined performing a rigorous mathematical optimization, aiming at calculating the set of design parameters maximizing (or minimizing) the selected objective function.

In this analysis, the selected objective functions (OFs) are the overall destroyed exergy, Ex $\mathrm{d}_{\mathrm{d}, \mathrm{tota}}$; the operating cost, $C_{o p}$; the exergy efficiency of the system, $\eta_{\mathrm{ex}}$; the profit index, PI. For each OF, the goal must be defined. In this case, in order to improve the system from the economic point of view, $C_{o p}$ was minimized and PI maximized. Instead, in order to improve the system from the thermodynamic point of view, Exd,total was minimized and $\eta_{\mathrm{ex}}$ maximized. Nsc, NeFF, vTK1 and $\mathrm{q}_{\mathrm{p} 4}$ are the design input variables. In Table 2 the final optimal solutions for each objective functions are shown.

Table 2. Optimal values for the objective functions of optimization analysis and comparison with initial values.

\begin{tabular}{|c|c|c|c|c|c|c|c|c|c|c|}
\hline \multirow[b]{2}{*}{ OFs } & \multicolumn{5}{|c|}{ Design variables } & \multicolumn{2}{|c|}{ Optimal } & \multicolumn{3}{|c|}{ Initial } \\
\hline & Goal & $\begin{array}{c}\mathbf{N}_{\mathbf{S C}} \\
-\end{array}$ & $\begin{array}{c}\mathbf{N}_{\mathrm{EFF}} \\
-\end{array}$ & $\begin{array}{c}\mathbf{v}_{\text {TK1 }} \\
\mathbf{L} \cdot \mathbf{m}^{-2}\end{array}$ & $\begin{array}{c}\mathbf{q}_{\mathrm{p} 4} \\
\mathbf{k g} \cdot \mathrm{h}^{-1}\end{array}$ & Value & Unit & OFs & Value & Unit \\
\hline PI & Max. & 760 & 14 & 25 & 475 & 3.43 & - & PI & 2.64 & - \\
\hline $\mathrm{C}_{\mathrm{op}}$ & Min. & 1000 & 14 & 25 & 620 & -2480 & $\mathrm{k} €$ & $\mathrm{C}_{\mathrm{op}}$ & -541 & $\mathrm{k} €$ \\
\hline$\eta_{\text {ex }}$ & Max. & 1000 & 9 & 25 & 100 & 12.80 & $\%$ & $\eta_{\text {ex }}$ & 7.20 & $\%$ \\
\hline Ex $_{\mathrm{d}, \text { total }}$ & Min. & 250 & 9 & 25 & 100 & 9.46 & $\mathrm{GWh} / \mathrm{y}$ & Ex $_{\text {d,total }}$ & 10.9 & $\mathrm{GWh} / \mathrm{y}$ \\
\hline
\end{tabular}

In the same table, the values of the OFs for the initial reference configuration of the plant $\left(\mathrm{N}_{\mathrm{EFF}}=8\right.$; $\left.\mathrm{NSC}_{\mathrm{SC}}=250 ; \mathrm{q}_{\mathrm{p}}=250 \mathrm{~kg} / \mathrm{h} ; \mathrm{VTK} 1=50 \mathrm{~L} / \mathrm{m}^{2}\right)$ are reported. The results of the optimization procedure indicate that the specific volume of the tank, vTK1, must be equal to the lower value of $25 \mathrm{~L} / \mathrm{m}^{2}$. In order to reach the maximum for $\eta_{\text {ex }}$ of $12.80 \%$ and the minimum for Exd,total of $9.46 \mathrm{GWh} / \mathrm{y}$, the number of effects of MED unit, $\mathrm{N}_{\mathrm{EFF}}$, is equal to 9 , and the specific flow rate, $\mathrm{qp}_{\mathrm{p}}$, is equal to $100 \mathrm{~kg} / \mathrm{h}$. As expected, in order to maximize the $\eta_{\mathrm{ex}}$, the highest number of collectors Nsc equal to 1000 , is required. The economic feasibility of the plant is obtained maximizing PI, equal to 3.43, respect to 2.64 of the reference configuration. This result is due to the higher number of MED effects and CPVT collectors, NeFF and NSC, respectively, equal to 14 and 760, and with qp4 equal to $475 \mathrm{~kg} / \mathrm{h}$. Conversely, $C_{o p}$ is reduced to $-2480 \mathrm{k} €$, respect to $-541 \mathrm{k} €$ of the reference configuration, when $\mathrm{q}_{\mathrm{p} 4}$ is equal to $620 \mathrm{~kg} / \mathrm{h}$ and $\mathrm{N}_{\mathrm{SC}}$ is equal to higher value.

\section{Conclusions}

In this paper, an optimization model and an exergy analysis of a Renewable Polygeneration System, consisted of CPVT, SHC, a MED unit, and an auxiliary boiler, for the production of thermal, electrical, cooling energy, and desalinated water, is presented.

The optimization model includes a computer-based design of experiments procedure aiming at determining, from the exergy-environmental and economic point of view, the optimal configuration of the plant varying the most important system design variables (solar collectors and MED effects number, P4 specific flow rate, TK specific volume). The optimization process was carried out for maximizing 
the exergy efficiency and the profit index and for minimizing the operation cost and the global destroyed exergy.

All simulations show that, the storage tank volumes should be relatively small ( $25 \mathrm{~L}$ per unit area of solar field). Regarding the economic objective functions, qp4 design variable should not exceed $475 \mathrm{~kg} / \mathrm{h}$. In addition, the optimal solution suggests both the installation of a high MED number of effects (namely: 14), in order to obtain greater public funding and economic savings by the desalinated water production, and the installation of about 760 collectors for maximizing PI and 1000 for minimizing $\mathrm{C}_{\mathrm{op}}$. Then, despite the high capital cost of the solar collectors, the economic optimization results suggest a greater capacity of the solar field. The same result occurs also for the global exergy efficiency, which has the maximum value of $12.8 \%$ for 1000 solar collectors. In this case, about $87.2 \%$ of the fuel exergy entering the system is destroyed. In fact, for minimizing the global destroyed exergy objective function, the solar collectors number must be low.

The exergy analysis has shown that the exergy flow related to the CPVT electrical production is higher than the thermal/cooling and MED ones. During the summer, a significant increase of both exergy fuels and products are achieved. This is due to the higher availability of solar radiation. The highest exergy destruction is achieved in the auxiliary heater $(\mathrm{AH})$ and in the solar field. In particular, during the hottest summer days, solar exergy becomes extremely high and it is generally often higher than the one related to the biomass. The overall result of this analysis suggests that the system exergy efficiency is poor. Although the system is based on renewable energy source, their exergy utilization is very difficult. In fact, according to the results of the optimization, solar energy use determines large irreversibilities due to the high temperature difference between the sun the operating fluid.

\section{Author Contributions}

All authors contributed to this work. In particular, Antonio Piacentino mainly focused on the MED subsystem developing energetic and exergetic models. Massimo Dentice and Francesco Calise developed the overall dynamic simulation model. Maria Vicidomini implemented the DoE technique. All authors revised and approved the manuscript.

\section{Nomenclature}

$\begin{array}{cl}A & \text { Area }\left(\mathrm{m}^{2}\right) \\ A F & \text { Annuity Factor (years) } \\ B C & \text { Incomes from trading of } \mathrm{CO}_{2} \text { emission certificates }(€ / \text { year }) \\ { }^{c} & \text { Specific heat }(\mathrm{kJ} / \mathrm{kg} \mathrm{K}) \\ c_{\mathrm{CO}_{2}} & \text { Unit economic value for the } \mathrm{CO}_{2} \text { emission saving }\left(€ / \mathrm{kgCO}_{2}\right) \\ C_{o p} & \text { Annual operating cost }(€ / \text { year }) \\ c_{p} & \text { Specific heat at constant pressure }(\mathrm{kJ} / \mathrm{kg} \mathrm{K}) \\ E_{e l} & \text { Electric energy }(\mathrm{kWh}) \\ \dot{E}_{e l} & \text { Electric power }(\mathrm{kW}) \\ e x & \text { Specific exergy }(\mathrm{kJ} / \mathrm{kg}) \\ \dot{E x} & \text { Exergy flow }(\mathrm{kW})\end{array}$




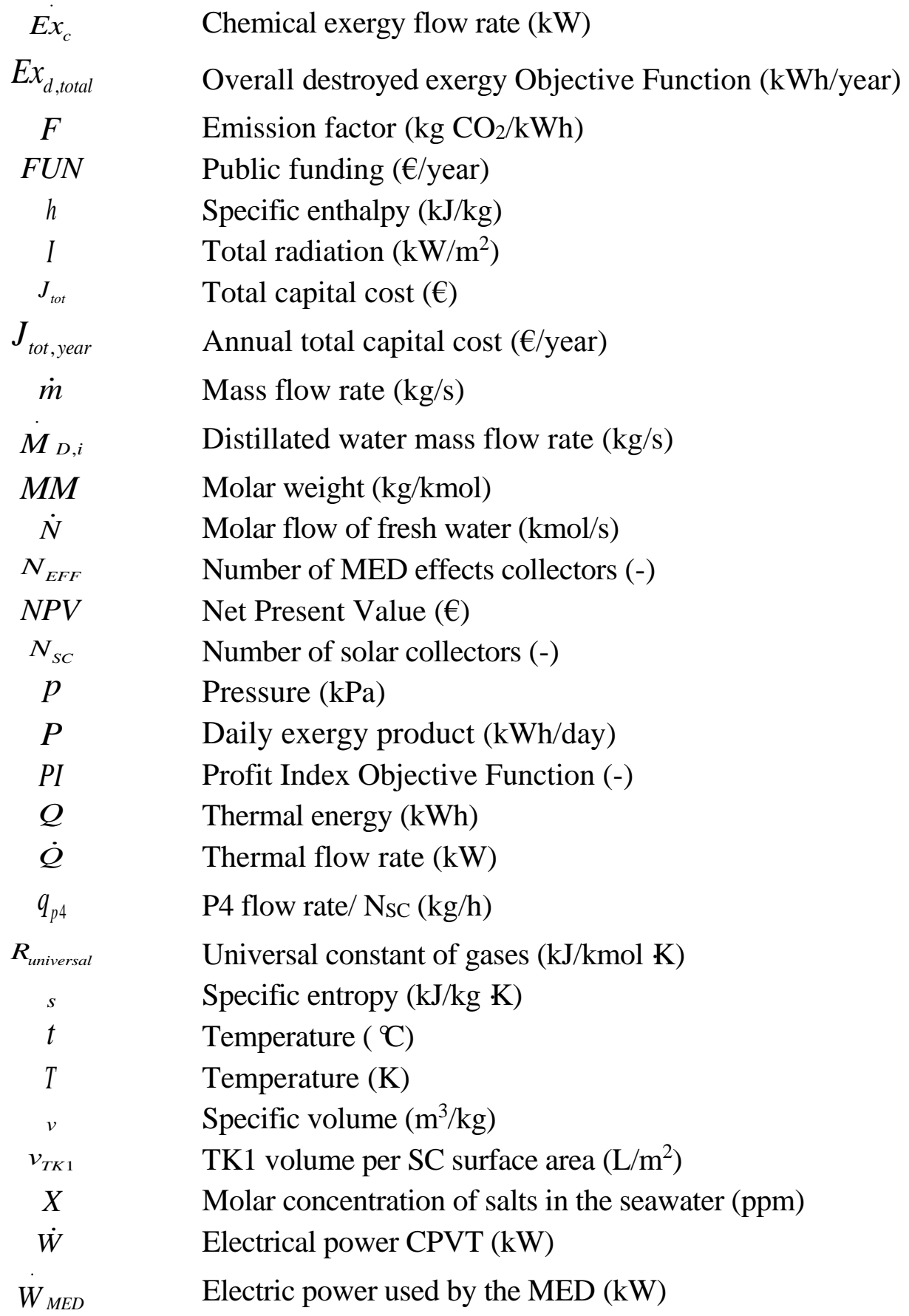

\section{Abbreviations}

$\mathrm{ACH}$

Absorption Chiller

$\mathrm{AH}$

Auxiliary Heater

BOP

Balance of Plant

CHW

Chilled Water

CPVT

Concentrating Photovoltaic-Thermal Collector

COP

Coefficient of Performance

$\mathrm{CW}$

Cooling Water

$\mathrm{D}$

Diverter

DoE

Design of Experiment 


$\begin{array}{cl}\text { DHW } & \text { Domestic Hot Water } \\ \text { DW } & \text { Desalted water } \\ \text { HE } & \text { Heat exchanger } \\ \text { HF } & \text { Hot fluid } \\ \text { HW } & \text { Hot water } \\ \text { M } & \text { Mixer } \\ \text { MED } & \text { Multiple-Effect Distillation } \\ \text { MSF } & \text { Multi-Stage Flash } \\ \text { P } & \text { Pump } \\ \text { PVT } & \text { Photovoltaic-Thermal collectors } \\ \text { RO } & \text { Reverse Osmosis } \\ \text { RPS } & \text { Renewable Polygeneration System } \\ \text { SCF } & \text { Solar Collector Fluid } \\ \text { SHC } & \text { Solar Heating and Cooling } \\ \text { SW } & \text { Seawater } \\ \text { TK } & \text { Tank }\end{array}$

\section{Greek Symbols}

$\begin{array}{cl}\varphi & \text { Dissociation factor }(-) \\ \omega_{t h} & \text { Theoretical minimum work of separation }(\mathrm{kJ} / \mathrm{kmol}) \\ \vartheta & \text { Temperature }(\mathrm{K}) \\ \eta & \text { Efficiency (-) } \\ \eta_{e x} & \text { Exergy efficiency (-) }\end{array}$

\section{Subscripts}

$\begin{array}{cl}a & \text { Ambient } \\ \text { aux } & \text { Auxiliary } \\ A H & \text { Auxiliary Heater } \\ B & \text { Brine } \\ \text { biomass } & \text { Biomass } \\ c & \text { Chemical } \\ \text { cond } & \text { Condensing } \\ \text { CPVT } & \text { Concentrating Photovoltaic-Thermal Collector } \\ d & \text { Destroyed } \\ D, \text { flash } i & \text { Distillate produced by flash at brine inlet at } i \text {-th effect } \\ D H W & \text { Domestic Hot Water } \\ D, i & \text { Distillate by evaporation at } i \text {-th effect } \\ e l & \text { Electrical } \\ \text { ex } & \text { Exergy } \\ \text { feed } & \text { Seawater in input to the plant } \\ \text { fresh } & \text { Related to the fresh water produced }\end{array}$




$\begin{array}{cl}h & \text { Heating } \\ i & i \text {-th time-step } \\ M E D & \text { Multi-Effect Distillation } \\ N G & \text { Natural gas } \\ p h & \text { Physics } \\ s & \text { Salts } \\ \text { sun } & \text { Sun } \\ t & \text { Traditional } \\ \text { tot } & \text { Total }\end{array}$

\section{Conflicts of Interest}

The authors declare no conflict of interest.

\section{References}

1. Agency, I.-I.E., Ed. World Energy Outlook 2013; OECD/IEA: Paris, France, 2013.

2. IEA. Current Research Projects (Tasks). Available online: http://www.iea-shc.org/tasks-current (accessed on 27 January 2015).

3. Sarbu, I.; Sebarchievici, C. Review of solar refrigeration and cooling systems. Energy Build. 2013, 67, 286-297.

4. Ullah, K.R.; Saidur, R.; Ping, H.W.; Akikur, R.K.; Shuvo, N.H. A review of solar thermal refrigeration and cooling methods. Renew. Sustain. Energy Rev. 2013, 24, 499-513.

5. Zhai, X.Q.; Qu, M.; Wang, R.Z. A review for research and new design options of solar absorption cooling systems. Renew. Sustain. Energy Rev. 2011, 15, 4416-4423.

6. Angrisani, G.R.C.; Sasso, M.; Tariello, F. Assessment of energy, environmental and economic performance of a solar desiccant cooling system with different collector types. Energies 2014, 7 , 6741-6764.

7. Calise, F.; Palombo, A.; Vanoli, L. Design and dynamic simulation of a novel solar trigeneration system based on photovoltaic/thermal collectors. Energy Convers. Manag. 2011, 60, 214-225.

8. Chow, T.T. A review on photovoltaic/thermal hybrid solar technology. Appl. Energy 2010, 87, 365-379.

9. Zondag, H.A. Flat-plate PV-Thermal collectors and systems: A review. Renew. Sustain. Energy Rev. 2008, 12, 891-895.

10. Mittelman, G.; Kribus, A.; Dayan, A. Solar cooling with concentrating photovoltaic/thermal (CPVT) systems. Energy Convers. Manag. 2007, 48, 2481-2490.

11. Ibrahim, A.; Othman, M.; Ruslan, M.H.; Mat, S.; Sopian, K. Recent advances in flat plate photovoltaic/thermal (PV/T) solar collectors. Renew. Sustain. Energy Rev. 2011, 15, 352-365.

12. Nishioka, K.; Takamoto, T.; Agui, T.; Kaneiwa, M.; Uraoka, Y.; Fuyuki, T. Annual output estimation of concentrator photovoltaic systems using high-efficiency InGaP/InGaAs/Ge triple-junction solar cells based on experimental solar cell's characteristics and field-test meteorological data. Solar Energy Mater. Sol. Cells 2006, 90, 57-67. 
13. Desalination.com. What Technologies Are Used? 2012. Available online: http://www.desalination.com/market/technologies (accessed on 18 June 2013).

14. Tokui, Y.; Moriguchi, H.; Nishi, Y. Comprehensive environmental assessment of seawater desalination plants: Multistage flash distillation and reverse osmosis membrane types in Saudi Arabia. Desalination 2014, 351, 145-150.

15. Cardona, E.; Piacentino, A. Optimal design of cogeneration plants for seawater desalination. Desalination 2004, 166, 411-426.

16. Ibrahim, S.; Al-Mutaz, A.M.A.-N. Characteristics of dual purpose MSF desalination plants. Desalination 2004, 166, 287-294.

17. Cardona, E.; Piacentino, A.; Marchese, F. Performance evaluation of CHP hybrid seawater desalination plants. Desalination 2007, 205, 1-14.

18. Osman, A.; Hamed, H.A.A.-O. Prospects of operation of MSF desalination plants at high TBT and low antiscalant dosing rate. Desalination 2010, 256, 181-189.

19. Esfahani, I.J.; Ataei, A.; Shetty K.V.; Oh, T.; Park, J.H.; Yoo, C. Modeling and genetic algorithm-based multi-objective optimization of the MED-TVC desalination system. Desalination 2012, 292, 87-104.

20. Palenzuela, P.; Hassan, A.S.; Zaragoza, G.; Alarcón-Padilla, D.-C. Steady state model for multi-effect distillation case study: Plataforma Solar de Almería MED pilot plant. Desalination 2014, 337, 31-42.

21. Calise, F.; d'Accadia, M.D.; Piacentino, A. A novel solar trigeneration system integrating PVT (photovoltaic/thermal collectors) and SW (seawater) desalination: Dynamic simulation and economic assessment. Energy 2014, 67, 129-148.

22. Calise, F.; Cipollina, A.; d'Accadia, M.D.; Piacentino, A. A novel renewable polygeneration system for a small mediterranean volcanic island for the combined production of energy and water: Dynamic simulation and economic assessment. Appl. Energy 2014, 135, 675-693.

23. Koroneos, C.; Tsarouhis, M. Exergy analysis and life cycle assessment of solar heating and cooling systems in the building environment. J. Clean. Prod. 2012, 32, 52-60.

24. Onan, C.; Ozkan, D.B.; Erdem, S. Exergy analysis of a solar assisted absorption cooling system on an hourly basis in villa applications. Energy 2010, 35, 5277-5285.

25. Calise, F.; Palombo, A.; Vanoli, L. A finite-volume model of a parabolic trough photovoltaic/thermal collector: Energetic and exergy analyses. Energy 2012, 46, 283-294.

26. El-Nashar, M.A.; Al-Baghdadi, A.A. Exergy losses in a multiple-effect stack seawater desalination plant. Desalination 1998, 116, 11-24.

27. Nafey, A.S.; Fath, H.E.S.; Mabrouk, A.A. Exergy and thermoeconomic evaluation of MSF process using a new visual package. Desalination 2006, 201, 224-240.

28. Sharaf, M.A.; Nafey, A.S.; García-Rodríguez, L. Exergy and thermo-economic analyses of a combined solar organic cycle with multi effect distillation (MED) desalination process. Desalination 2011, 272, 135-147.

29. Sharqawy, M.H.; Lienhard, V.J.H.; Zubair, S.M. On exergy calculations of seawater with applications in desalination systems. Int. J. Therm. Sci. 2011, 50, 187-196.

30. Al-Weshahi, M.A.; Anderson, A.; Tian, G. Exergy efficiency enhancement of MSF desalination by heat recovery from hot distillate water stages. Appl. Therm. Eng. 2013, 53, 226-233. 
31. Nematollahi, F.; Rahimi, A.; Gheinani, T.T. Experimental and theoretical energy and exergy analysis for a solar desalination system. Desalination 2013, 317, 23-31.

32. Jin, C.-Z.; Chou, Q.L.; Jiao, D.S.; Shu, P.C. Vapour compression flash seawater desalination system and its exergy analysis. Desalination 2014, 353, 75-83.

33. Uche, J.; Serra, L.; Valero, A. Thermoeconomic optimization of a dual-purpose power and desalination plant. Desalination 2001, 136, 147-158.

34. Fiorini, P.; Sciubba, E. Modular simulation and thermoeconomic analysis of a multi-effect distillation desalination plant. Energy 2007, 32, 459-466.

35. Mabrouk, A.A.; Nafey, A.S.; Fath, H.E.S. Thermoeconomic analysis of some existing desalination processes. Desalination 2007, 205, 354-373.

36. Sayyaadi, H.; Saffari, A. Thermoeconomic optimization of multi effect distillation desalination systems. Appl. Energy 2010, 87, 1122-1133.

37. Sayyaadi, H.; Saffari, A.; Mahmoodian, A. Various approaches in optimization of multi effects distillation desalination systems using a hybrid meta-heuristic optimization tool. Desalination 2010, 254, 138-148.

38. Hosseini, S.R.; Amidpour, M.; Behbahaninia, A. Thermoeconomic analysis with reliability consideration of a combined power and multi stage flash desalination plant. Desalination 2011, $278,424-433$.

39. Li, M.; Ji, X.; Li, G.L.; Yang, Z.M.; Wei, S.X.; Wang, L.L. Performance investigation and optimization of the Trough Concentrating Photovoltaic/Thermal system. Sol. Energy 2011, 85, 1028-1034.

40. El-Emam, R.S.; Dincer, I. Thermodynamic and thermoeconomic analyses of seawater reverse osmosis desalination plant with energy recovery. Energy 2014, 64, 154-163.

41. Calise, F.; d'Accadia, M.D.; Vanoli, L. Thermoeconomic optimization of Solar Heating and Cooling systems. Energy Convers. Manag. 2011, 52, 1562-1573.

42. Hang, Y.; Du, L.; Qu, M.; Peeta, S. Multi-objective optimization of integrated solar absorption cooling and heating systems for medium-sized office buildings. Renew. Energy 2013, 52, 67-78.

43. Zou, Z.; Guan, Z.; Gurgenci, H. Optimization design of solar enhanced natural draft dry cooling tower. Energy Convers. Manag. 2013, 76, 945-955.

44. Wang, M.; Wang, J.; Zhao, P.; Dai, Y. Multi-objective optimization of a combined cooling, heating and power system driven by solar energy. Energy Convers. Manag. 2015, 89, 289-297.

45. Calise, F. Thermoeconomic analysis and optimization of high efficiency solar heating and cooling systems for different Italian school buildings and climates. Energy Build. 2010, 42, 992-1003.

46. Sharaf, O.Z.; Orhan, M.F. Concentrated photovoltaic thermal (CPVT) solar collector systems: Part II-Implemented systems, performance assessment, and future directions. Renew. Sustain. Energy Rev. 2014, doi:10.1016/j.rser.2014.07.215.

47. Calise, F.; d'Accadia, M.D.; Vanoli, L. Design and dynamic simulation of a novel solar trigeneration system based on hybrid photovoltaic/thermal collectors (PVT). Energy Convers. Manag. 2012, 60, 214-225.

48. Evola, G.; Marletta, L. Exergy and thermoeconomic optimization of a water-cooled glazed hybrid photovoltaic/thermal (PVT) collector. Sol. Energy 2014, 107, 12-25. 
49. Khoshgoftar Manesh, M.H.; Ghalami, H.; Amidpour, M.; Hamedi, M.H. Optimal coupling of site utility steam network with MED-RO desalination through total site analysis and exergoeconomic optimization. Desalination 2013, 316, 42-52.

50. Walpole, R.E.; Myers, R.H.; Myers, S.L.; Ye, K.E. Probability and Statistics for Engineers and Scientists, 9th ed.; Pearson: Upper Saddle River, NJ, USA, 1993.

51. Calise, F.; Palombo, A.; Vanoli, L. Maximization of primary energy savings of solar heating and cooling systems by transient simulations and computer design of experiments. Appl. Energy 2010, 87, 524-540.

52. Rosen, M.A.; Dincer, I. Effect of varying dead-state properties on energy and exergy analyses of thermal systems. Int. J. Therm. Sci. 2004, 43, 121-133.

53. Kotas, T.J. The Exergy Method of Thermal Plant Analysis; Paragon Publishing: Wiltshire, UK, 1995.

54. Torío, H.; Angelotti, A.; Schmidt, D. Exergy analysis of renewable energy-based climatisation systems for buildings: A critical view. Energy Build. 2009, 41, 248-271.

55. Ajam, H.; Farahat, S.; Saehaddi, F. Exergy Optimization of solar air heaters and comparison with energy analysis. Int. J. Thermodyn. 2005, 8, 183-190.

56. Song, G.; Shen, L.; Xiao, J. Estimating specific chemical exergy of biomass from basic analysis data. Ind. Eng. Chem. Re. 2011, 50, 9758-9766.

57. Spiegler, K.S.; El-Sayed, Y.M. The energetics of desalination processes. Desalination 2001, 134, 109-128.

(C) 2015 by the authors; licensee MDPI, Basel, Switzerland. This article is an open access article distributed under the terms and conditions of the Creative Commons Attribution license (http://creativecommons.org/licenses/by/4.0/). 